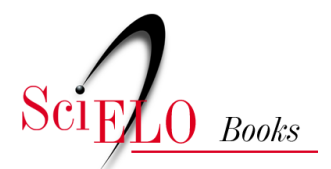

\title{
La teoría desde los Enfoques Axiomático, Estructural y Semántico. Distinciones, Elementos y articulaciones
}

\author{
José Enrique Juncosa Blasco \\ Luis Fernando Garcés Velásquez
}

\section{SciELO Books / SciELO Livros / SciELO Libros}

JUNCOSA BLASCO, J. E., and GARCÉS VELÁSQUEZ, L. F. La teoría desde los Enfoques Axiomático, Estructural y Semántico. Distinciones, Elementos y articulaciones. In: ¿Qué es la teoría? Enfoques, usos y debates en torno al pensamiento teórico [online]. Quito: Editorial Abya-Yala, 2020, pp. 117-178. ISBN: 978-9978-10-543-6. http://doi.org/10.7476/9789978105788.0003.

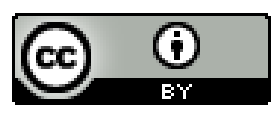

All the contents of this work, except where otherwise noted, is licensed under a Creative Commons Attribution 4.0 International license.

Todo o conteúdo deste trabalho, exceto quando houver ressalva, é publicado sob a licença Creative Commons Atribição 4.0.

Todo el contenido de esta obra, excepto donde se indique lo contrario, está bajo licencia de la licencia Creative Commons Reconocimento 4.0. 


\section{Capítulo II LA TEORÍA DESDE LOS ENFOQUES AXIOMÁTICO, ESTRUCTURAL Y SEMÁNTICO. DISTINCIONES, ELEMENTOS Y ARTICULACIONES ${ }^{21}$}

\section{Introducción}

La revisión de las propuestas de Popper, Horkheimer, Habermas y Morin nos ha permitido acceder a las características fundamentales de la teoría desde un punto de vista crítico respecto a otras funciones adaptativas (los mecanismos genéticos), las capacidades aprendidas, los sistemas mentales (la ideología y la doctrina), la racionalidad instrumental. Otras aproximaciones, propias de la filosofía de la ciencia, identifican con mayor precisión los elementos sincrónicos que constituyen las teorías y sus respectivas relaciones.

El itinerario de este apartado inicia con la consideración de las distinciones básicas e indispensables de la teoría respecto al sentido común y la ley científica, y continúa con la identificación de los

21 Este capítulo retoma, amplía y profundiza el apartado "Las teorías como instrumentos complejos de conocimiento", del marco teórico de Juncosa, José Enrique. (2006). Teorias del conocimiento en experiencias universitarias con movimientos sociales. Un aporte para la carrera de Antropología Aplicada de la Universidad Politécnica Salesiana. (Tesis de maestría inédita en Desarrollo de la Inteligencia y Educación). Universidad Técnica Particular de Loja, Pontificia Universidad Católica del Ecuador. Ibarra, pp. 61-77. 
elementos que componen la arquitectura de la teoría según varias perspectivas: la axiomática, la historicista, la semántica y, finalmente, una prolongación de esta última corriente: la estructuralista ${ }^{22}$; todas ellas ofrecen diversas posibilidades para identificar los elementos constitutivos de las teorías y definir sus relaciones. La concepción axiomática asume que las teorías son reductibles a formulaciones lógicas y sus elementos básicos equivalen a los términos. El valor de validez o invalidez se relaciona con la coherencia lógica y formal y, por lo tanto, su escenario de control es la lógica. La concepción historicista, en cambio, enfoca la teoría desde el punto de vista del cambio; es decir, estableciendo elementos perdurables y constantes y otros menos estables que giran alrededor de ellos. El historicismo se basa en el carácter de pertinencia histórica como criterio de validez o invalidez de una teoría y su escenario de control es la sociología de la ciencia, pues, en definitiva, o es la comunidad científica la que establece la validez de una teoría o es la sociedad en su conjunto la que la ratifica al considerarla útil y pertinente. Finalmente, la propuesta semántica considera que toda teoría es una forma de representación del conocimiento sobre la realidad y enfatiza el hecho de que las teorías se comportan como modelos para interpretar y solucionar problemas. Los criterios de validez o invalidez se relacionan, entonces, con la capacidad modélica que posee un caso real o un esquema lógica para lograr la comprensión de otros casos.

22 Las diferencias entre teoría, sentido común y ley científica se basan en el criterio ampliamente difundido de Ernest Nagel (1991). La descripción de las corrientes metateóricas de la filosofía de la ciencia se basa en los aportes del mismo Nagel y otros autores como Carl G. Hempel (2005), Van Fraassen (1996), así como en las sistematizaciones de Díez y Moulines (1997) y Lorenzano (2002). 


\section{Distinciones básicas: teoría y sentido común. Teoría y ley cientifica}

Por lo general, los manuales de filosofía de la ciencia abordan la distinción entre teoría y sentido común como realidades opuestas e irreductibles entre sí, sin tomar en cuenta que son continuas y se relacionan entre sí. A continuación, contrastaremos ambos saberes con fines didácticos y con la precaución de considerar ambas como instancias en permanente interacción en la generación de conocimientos. En la mayoría de casos, las teorías corren el riesgo de constituirse en sentido común cuando el investigador las incorpora como realidades dadas de su acerbo cognitivo, cuando ya no son objeto de la crítica reflexiva y pierden, por ello, el carácter instrumental que las anima. Observamos, incluso, que en la cultura contemporánea la teoría ha llegado a ser un objeto de consumo de masas mediante la difusión de la ciencia en programas televisivos, artículos periodísticos y publicaciones, difusión que en muchos casos adquiere los tintes de banalización de la ciencia. Por tanto, también en este escenario la teoría ha infiltrado el sentido común colectivo para incorporarse en el lenguaje y las preocupaciones cotidianas de la sociedad.

El aporte del filósofo Thomas Nagel (1991, pp. 15-38) contribuye a entender las teorías, tanto desde el contexto de las ciencias formales cuanto de las naturales y sociales, a partir de la distinción entre dos formas fundamentales de conocimiento a las que el autor considera estrategias explicativas y predictivas diversas: el sentido común y la ciencia. Según el autor, esta última, en tanto arte institucionalizado de la investigación, permite obtener conocimientos teóricos generales respecto a las condiciones de aparición de sucesos y procesos, y hace posible emancipar la mente de supersticiones antiguas y creencias tradicionales. La segunda línea divisoria es aquella 
que distingue la teoría con respecto a la ley científica, dos elementos distintos pero que constituyen las expresiones elementales de la metateoría. La Figura 7 grafica, de manera muy general, las relaciones de subordinación e inclusión entre estos diversos sistemas explicativos y predictivos.

Figura 7

Ciencia y sentido común según Nagel

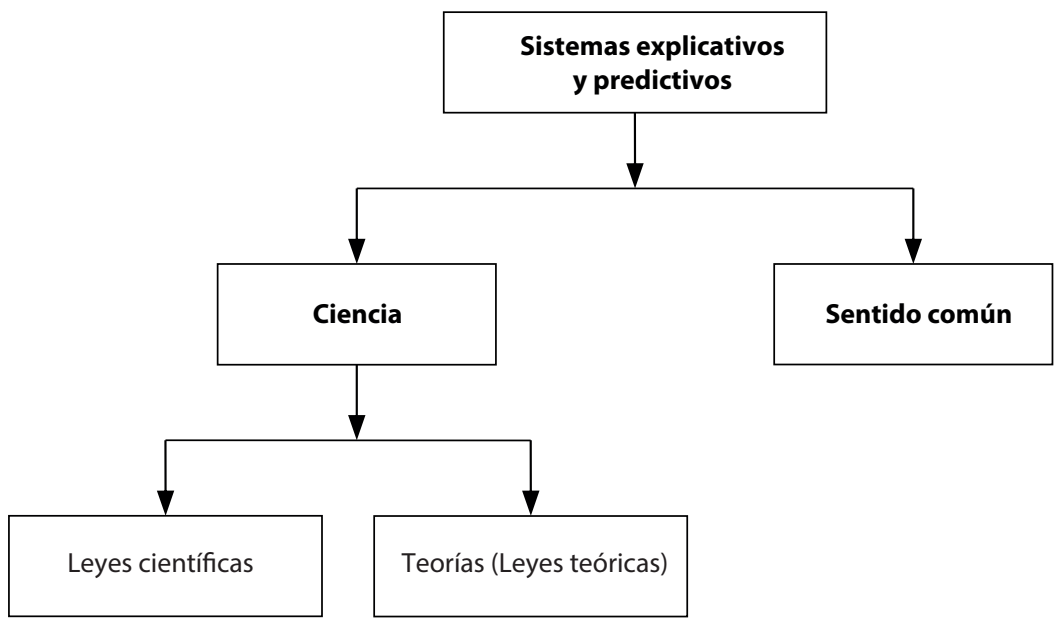

Elaboración de los autores a partir de Nagel (1991).

La Tabla 6, en cambio, sistematiza más o menos in extenso la caracterización contrastada de los principales sistemas explicativos: el sentido común y la ciencia, según las siguientes variables: explicación sistemática, restricción de la validez, antagonismos, lenguaje y orientación, y testabilidad. 
Tabla 6

Contrastación entre sentido común y ciencia

\begin{tabular}{|c|c|}
\hline \multicolumn{2}{|c|}{ Conocimiento (estrategias explicativas) } \\
\hline Sentido común (SC) & Ciencia $(C)$ \\
\hline \multicolumn{2}{|c|}{ Explicación sistemática } \\
\hline $\begin{array}{l}\text { Las conclusiones del sentido común tie- } \\
\text { nen continuidad con la ciencia. } \\
\text { La información adquirida en la expe- } \\
\text { riencia cotidiana es bastante exacta, pero } \\
\text { no está acompañada de una explicación } \\
\text { de por qué los hechos son como se pre- } \\
\text { sentan; cuando explica carece de pruebas } \\
\text { críticas de su vinculación con los hechos. }\end{array}$ & $\begin{array}{l}\text { Surge de las preocupaciones cotidianas: } \\
\text { - cuerpo de conocimiento organizado; } \\
\text { - clasificación de sus materiales en tipos o géneros } \\
\text { significativos. } \\
\text { Su origen es el deseo de hallar explicaciones sistemá- } \\
\text { ticas y controlables por elementos de juicio fáctico. } \\
\text { Su objetivo lo concreta sobre la base de principios } \\
\text { explicativos; descubre - para luego formular en } \\
\text { términos generales- condiciones de los fenóme- } \\
\text { nos; los enunciados de estos son las explicaciones; } \\
\text { este desarrollo se da aislando propiedades, diferen- } \\
\text { ciando esquemas de dependencia y encontrando } \\
\text { vinculaciones e interconexiones sistemáticas. }\end{array}$ \\
\hline \multicolumn{2}{|c|}{ Restricción de la validez } \\
\hline $\begin{array}{l}\text { Conocimiento incompleto y no erróneo, } \\
\text { por la falta de conciencia de los límites } \\
\text { dentro de los cuales sus creencias tienen } \\
\text { validez. } \\
\text { El conocimiento del SC se aplica supo- } \\
\text { niendo la permanencia de factores o per- } \\
\text { sistencia de condiciones; ello no quiere } \\
\text { decir que sus efectos sean erróneos ni sus- } \\
\text { ceptibles de cambio (a veces duran siglos). }\end{array}$ & $\begin{array}{l}\text { La ciencia sistemática completa el defecto del } \\
\text { conocimiento del SC: introduce agudeza en las } \\
\text { creencias al manifestar conexiones sistemáticas } \\
\text { de proposiciones del SC; muestra que las prác- } \\
\text { ticas comunes son explicables por principios que } \\
\text { formulan relaciones entre distintos puntos de } \\
\text { amplios ámbitos de hechos. }\end{array}$ \\
\hline \multicolumn{2}{|c|}{ Antagonismos } \\
\hline $\begin{array}{l}\text { Las contradicciones del SC se originan } \\
\text { en su contenido: es referido a efectos que } \\
\text { tienen las cosas corrientes sobre cuestio- } \\
\text { nes que los hombres valoran. } \\
\text { - } \mathrm{Ni} \text { se observan relaciones entre } \\
\text { fenómenos. } \\
\text { - Ni se explican sistemáticamente inde- } \\
\text { pendientemente de su impacto sobre las } \\
\text { preocupaciones humanas. }\end{array}$ & $\begin{array}{l}\text { Los juicios antagónicos son estímulos porque la } \\
\text { ciencia los combate con: } \\
\text { - explicaciones sistemáticas de hechos, discerni- } \\
\text { miento de condiciones y consecuencias de sucesos; } \\
\text { - evidencia de las relaciones lógicas entre } \\
\text { proposiciones. } \\
\text { Pese a que no existen garantías de ausencia de } \\
\text { contradicciones, cuando las hay, o son aparentes } \\
\text { o genuinas, pero transitorias. }\end{array}$ \\
\hline
\end{tabular}




\begin{tabular}{|c|c|}
\hline \multicolumn{2}{|c|}{ Conocimiento (estrategias explicativas) } \\
\hline Sentido común (SC) & Ciencia $(C)$ \\
\hline \multicolumn{2}{|c|}{ Características del lenguaje } \\
\hline $\begin{array}{l}\text { El lenguaje corriente presenta indeter- } \\
\text { minación (vaguedad e inespecificidad) y } \\
\text { ello dificulta el control experimental de } \\
\text { las creencias por la imposibilidad de es- } \\
\text { tablecer diferencias entre juicios confir- } \\
\text { matorios y contradictorios de aquellas. } \\
\text { Es esta indeterminación la que explica la } \\
\text { estabilidad de muchas creencias. }\end{array}$ & $\begin{array}{l}\text { Introduce modificaciones en el lenguaje para una } \\
\text { mayor determinación porque busca explicacio- } \\
\text { nes sistemáticas. Por su precisión, los enuncia- } \\
\text { dos se hacen más susceptibles de ser sometidos } \\
\text { a pruebas y críticas por medio de la experiencia } \\
\text { (enfrentan mayores riesgos de ser refutados por } \\
\text { los datos empíricos). } \\
\text { Por el incremento de la determinación de sus } \\
\text { enunciados y su incorporación a sistemas expli- } \\
\text { cativos lógicamente integrados, la C: } \\
\text { - agudiza su poder discriminatorio frente a las } \\
\text { pruebas; } \\
\text { - acrecienta la fuente de sus elementos de juicio } \\
\text { para sus conclusiones. }\end{array}$ \\
\hline \multicolumn{2}{|c|}{ Orientación; términos } \\
\hline $\begin{array}{l}\text { Limitada a la influencia de sucesos sobre } \\
\text { cuestiones que son objeto de valoracio- } \\
\text { nes por los hombres. } \\
\text { Conceptos abstractos. }\end{array}$ & $\begin{array}{l}\text { Ilimitada en sus preocupaciones; de ahí que los } \\
\text { enunciados científicos parezcan remotamente re- } \\
\text { lacionados con las cosas cotidianas. } \\
\text { Conceptos abstractos en relación no obvia con lo } \\
\text { cotidiano; presentan lejanía con lo ordinario por } \\
\text { su búsqueda de explicaciones de largo alcance (y } \\
\text { estas, siendo explicaciones de lo vario, se formu- } \\
\text { lan como propiedades estructurales sin referencia } \\
\text { a relaciones individualizantes de lo cotidiano). }\end{array}$ \\
\hline \multicolumn{2}{|c|}{ Testabilidad } \\
\hline $\begin{array}{l}\text { No sometidas a escrutinio sistemático } \\
\text { para determinar la exactitud y validez de } \\
\text { creencias. } \\
\text { Son aceptadas sin evaluación crítica. }\end{array}$ & $\begin{array}{l}\text { Sometida al desafío de datos observacionales crí- } \\
\text { ticamente probatorios. El que las hipótesis expli- } \\
\text { cativas sean testables significa que están abiertas } \\
\text { a la posibilidad de rechazo, según procedimientos } \\
\text { críticos. } \\
\text { La crítica se realiza con el fin de } \\
\text { - juzgar la confiabilidad de los procedimientos; } \\
\text { - evaluar la fuerza probatoria de los elementos de } \\
\text { juicio de las conclusiones. }\end{array}$ \\
\hline
\end{tabular}

Elaboración de los autores a partir de Fernández y Barbosa (1996, pp. 37-38). 
Otra de las distinciones clave de Nagel es la de ley experimental y ley teórica, a las que considera formas proposicionales o enunciados con forma gramatical propia que expresan distintos niveles de las categorías del conocimiento científico. Ambas desempeñan el papel de sistemas explicativos y predictivos, y funcionan como suposiciones; las leyes experimentales se refieren a fenómenos "observables" y las leyes teóricas, de carácter más vasto y abstracto, no se relacionan con fenómenos observables, aunque los incluyen en sus términos. Sin embargo, entre ambas categorías no existe una ruptura o división radical, sino que forman parte de un continuum. En la Tabla 7 apreciamos los caracteres esenciales de ambos tipos de categorías, según el mismo Nagel (1991, pp. 84 y ss.).

\section{Tabla 7}

Contrastación entre ley experimental y teoría

\begin{tabular}{|c|c|}
\hline \multicolumn{2}{|c|}{ Conocimiento teórico } \\
\hline Leyes experimentales & Leyes teóricas (teorías) \\
\hline $\begin{array}{l}\text { Enunciado que formula una relación en- } \\
\text { tre cosas o características de cosas que son } \\
\text { observables. } \\
\text { No significa que se deducen de experimentos } \\
\text { de laboratorio. } \\
\text { La ley puede ser convalidada con cierto } \\
\text { grado de probabilidad por la observación } \\
\text { controlada. }\end{array}$ & $\begin{array}{l}\text { Suposiciones no relacionadas con fenómenos } \\
\text { observables. } \\
\text { No significa que son puramente especulativas. } \\
\text { Sus términos se refieren a algo no manifies- } \\
\text { tamente observable ni confirmable mediante } \\
\text { experimentos u observaciones de las cosas a } \\
\text { los que se refieren. }\end{array}$ \\
\hline $\begin{array}{l}\text { Se expresan con términos abstractos, no solo } \\
\text { observacionales. }\end{array}$ & $\begin{array}{l}\text { Se expresan con términos abstractos, aunque } \\
\text { también incluyen fenómenos observacionales. }\end{array}$ \\
\hline $\begin{array}{l}\text { Contenido empírico determinado, contro- } \\
\text { lado por elementos observacionales según } \\
\text { procedimientos establecidos. }\end{array}$ & $\begin{array}{l}\text { Los términos de una teoría no se definen me- } \\
\text { diante procedimientos experimentales explí- } \\
\text { citos. Derivan de analogías generadoras. Una } \\
\text { teoría no puede ser sometida a una prueba } \\
\text { experimental directa. }\end{array}$ \\
\hline
\end{tabular}


124

\begin{tabular}{|l|l|}
\hline \multicolumn{2}{|c|}{ Conocimiento teórico } \\
\hline $\begin{array}{l}\text { Son generalizaciones inductivas basadas } \\
\text { en relaciones que se cumplen en los datos } \\
\text { observados. }\end{array}$ & $\begin{array}{l}\text { Una teoría no es una generalización a partir } \\
\text { de datos observacionales. Los datos sugieren } \\
\text { o apoyan teorías. } \\
\text { Su basa en elementos de juicio observacionales. } \\
\text { leyes empíricas. } \\
\text { La ley experimental tiene vida propia y puede } \\
\text { sobrevivir a la teoría, pero una ley es ininte- } \\
\text { ligible al margen de la teoría que la explica. } \\
\text { Lasendiones teóricas no pueden ser com- } \\
\text { prendidas separadamente de la teoría parti- } \\
\text { cular que las define. } \\
\text { Cuando se alteran los postulados básicos } \\
\text { cambia el significado de los términos básicos. } \\
\text { Una nueva teoría explica las leyes de la ante- } \\
\text { rior teoría más otras nuevas. }\end{array}$ \\
\hline $\begin{array}{l}\text { Sin excepción, una ley experimental se for- } \\
\text { mula por medio de un solo enunciado. }\end{array}$ & $\begin{array}{l}\text { Sistema de varios enunciados vinculados en- } \\
\text { tre sí. }\end{array}$ \\
$\begin{array}{l}\text { Las leyes explican hechos cualitativamente } \\
\text { similares y definidos: dominio estrecho de } \\
\text { explicación. }\end{array}$ & $\begin{array}{l}\text { Mayor generalidad y mayor poder explicativo. } \\
\text { Marcan dominios de hechos cualitativamen- } \\
\text { te dispares debido a su independencia de } \\
\text { la observación y el carácter simbólico de la } \\
\text { teoría. }\end{array}$ \\
$\begin{array}{l}\text { Dos funciones: a) Poner de manifiesto las co- } \\
\text { nexiones sistemáticas entre leyes experimenta- } \\
\text { les relacionadas con fenómenos de ámbito di- } \\
\text { verso; b) Suministra sugerencias para otras le- } \\
\text { yes experimentales y el método observacional. }\end{array}$ \\
\hline
\end{tabular}

Elaboración de los autores a partir de Nagel (1991, pp. 84 y ss.).

Como se puede observar en la Tabla 7, el aporte de Nagel menciona otros elementos como términos y nociones teóricas, elementos nucleares y constitutivos de la teoría que serán mejor explicados en el siguiente apartado referido a la concepción axiomática.

\section{Elementos de la teoría según la concepción axiomática}

La concepción axiomática es, sin duda, la postura más difundida que nutre muchas aproximaciones y aportes sobre filosofía de 
la ciencia. Concibe las teorías como cuerpos de conocimientos que articulan afirmaciones o enunciados organizados — proposicionesde distinto grado de abstracción según los principios de la gramática del lenguaje lógico. Las teorías son el conjunto previo de afirmaciones sobre determinados ámbitos de la realidad, de tal manera que "se analizan o reconstruyen como teniendo cierta estructura que expresa las relaciones que mantienen entre sí las diversas afirmaciones y los diversos términos o conceptos con los que se realizan tales afirmaciones" (Díez y Moulines, 1997, p. 268).

En el plano de sus componentes lógicos básicos, toda teoría (T) se expresa mediante un conjunto reducido de afirmaciones fundamentales y básicas que originan, mediante procesos de inferencia deductiva, a todas las demás. Los elementos básicos de una teoría son dos: a) Los axiomas o postulados $(A)$, proposiciones básicas, autónomas e independientes en el sentido de que no proceden ni se derivan de las restantes: son capaces de condensar lógicamente la teoría y poseen un carácter primitivo y originante; b) Los teoremas $(t)$ : son las proposiciones derivadas o deducidas de los axiomas, es decir, aquellas que los explicitan; por lo tanto, no contienen nueva información. Los axiomas y sus consecuencias lógicas son las instancias que definen realmente una teoría en tanto que los teoremas no añaden nueva información. Toda teoría, por lo tanto, puede ser expresada según la siguiente fórmula: $(T=A+t)$ y es susceptible de ser axiomatizada cuando se identifica el conjunto completo de sus afirmaciones o supuestos fundamentales que la constituyen.

Asimismo, una teoría admite axiomatizaciones alternativas y no necesariamente se atan a un solo esquema lógico. El proceso de axiomatización, por otra parte, no se funda en criterios de prioridad epistémica, es decir, no selecciona aquellas proposiciones "bien fundadas", sino que establece el orden en un cuerpo de afirmaciones 
previamente existentes que no requieren ser comprobados y funcionan como supuestos; así, el criterio de la axiomatización procede por medio de la identificación de contradicciones e implica tomar partido por ellas.

Las teorías incluyen otros elementos de carácter básico: los términos-conceptos o definiciones, los cuales son proposiciones diversas a los axiomas y teoremas cuya función es "capturar entidades de diverso tipo (objetos individuales, sus propiedades y relaciones) que conforman el ámbito de la realidad del que se ocupa la teoría” (Díez y Moulines, 1997, p. 269). Del mismo modo como los teoremas proceden de los axiomas, algunos términos tienen un valor previo y originante, de tal modo que de unos se deducen otros. Aquellos términos dotados de la capacidad de originar a otros se denominan términos primitivos. Las proposiciones definitorias se construyen de tres modos: como relatores (el término más la variable, propiedades o relaciones entre entidades), términos singulares (ser " 1 ”) y functores (funciones-operaciones entre individuos).

Si bien las definiciones son lógicamente eliminables y prescindibles ya "que no constituyen afirmaciones sustantivas de la teoría sino que expresan meras abreviaturas notacionales" (Díez y Moulines, 1997, p. 290), en la práctica una teoría resulta incomprensible sin ellas y son elementos de enorme valor en la economía intelectual para la comprensión teórica. La Figura 8 organiza visualmente los elementos de una teoría y sus relaciones.

Es posible entender mejor la articulación de los elementos que constituyen una teoría no solo a partir de la discriminación de sus elementos lógicos, sino también según el tipo de enunciados que los expresan (Gianella, 2003, p. 48). Así, toda teoría relaciona enunciados de distintos niveles conectados por relaciones de compatibilidad 
e implicación, y referidos a determinados dominios de la realidad. En las ciencias fácticas, las teorías admiten la concatenación de niveles diversos de enunciados de abstracción creciente (p. 48):

a. Los enunciados empiricos básicos que se refieren a descripciones, datos y observaciones directamente conectados con la base empírica de la teoría;

b. Las generalizaciones empiricas, indirectamente conectadas con la base empírica pues expresan universalizaciones absolutas, estadísticas o existenciales. Este nivel es todavía preteórico;

c. Los enunciados teóricos propiamente dichos que intentan dar cuenta totalmente en abstracto lo asumido por los otros dos niveles. Los enunciados teóricos son puros cuando la totalidad de sus términos son abstractos; o mixtos, cuando incluyen algún término observacional, es decir, referido a la realidad. Estos últimos se denominan reglas de correspondencia o principios puente porque conectan los términos abstractos con la realidad.

Figura 8

Elementos de la teoría según la concepción axiomática

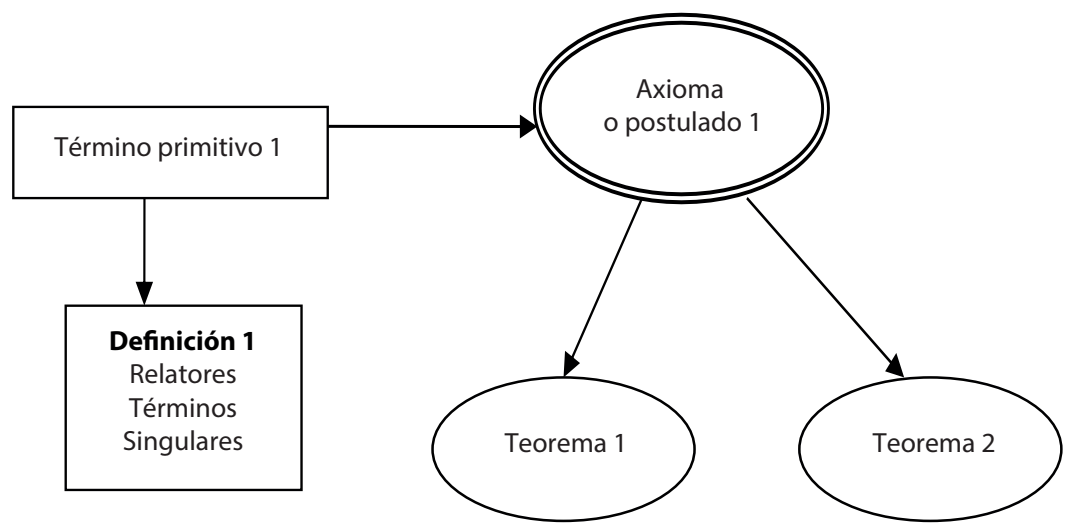

Elaboración de los autores a partir de Díez y Moulines (1997, pp. 268-290). 
La Figura 9 muestra la relación de los enunciados tal como los describe Gianella.

\section{Figura 9}

Elementos de los enunciados de los niveles preteórico y teórico

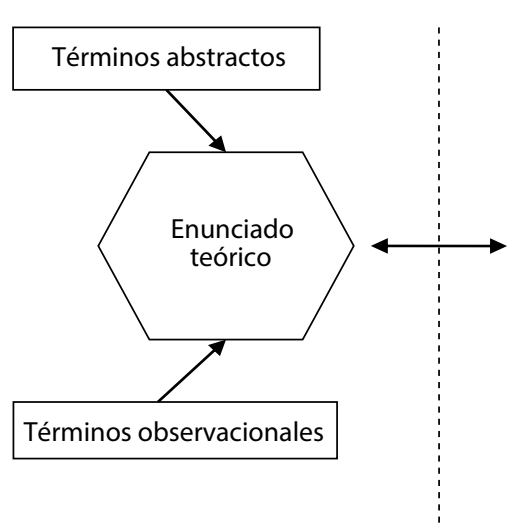

Nivel teórico

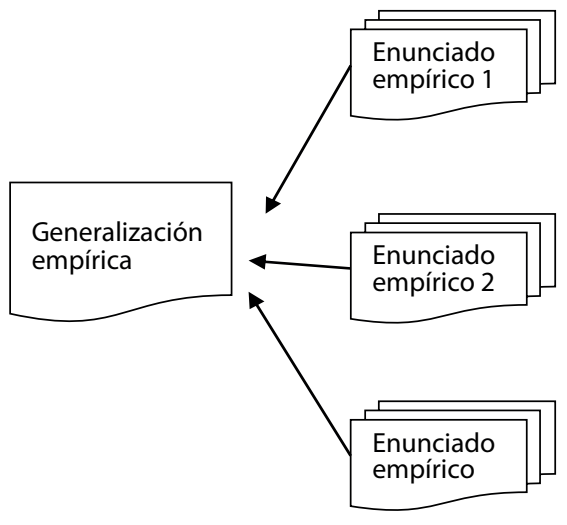

Nivel preteórico

Elaboración de los autores a partir de Gianella (2003, p. 48).

Entre los nudos más críticos de la propuesta, destacamos los siguientes: a) La problemática relación de continuidad entre el núcleo axiomático y la base empírica de la teoría (Díez y Moulines, 1997, pp. 297 y ss.), que consiste en la negación de la carga teórica del dato, un aspecto que ya hemos constatado gracias a Popper (su$p r a)$. Este aspecto es crucial porque la propuesta axiomática supone que la teoría es el resultado de sucesivas generalizaciones y, por lo tanto, esconde la pretensión de que los axiomas expresan la realidad. Sin embargo, todo dato u observación siempre están premoldeados por la teoría. b) Sustitución de la realidad y su sentido por los aspectos formales y lógicos de las teorías, según advierte y cuestiona Russell (Ribes, 1989, pp. 33 y ss.). c) La postura axiomática aspira a establecer un marco común universal de expresión y contenidos 
de conocimiento, en contravía con la diversidad y la novedad con el peligro de constituirse, según Feyerabend, en la expresión epistemológica de un orden político totalitario, no abierto a la diversidad.

No obstante, recalcamos aspectos a favor como el rigor lógico y la capacidad de identificar elementos estructurales y sus relaciones. En definitiva, aunque constituyen una dimensión importante de las teorías, los aspectos lógicos y formales no son los únicos que determinan una teoría ni pueden dar total cuenta de esta, como si se tratara de un cuerpo de conocimientos autorreferenciado, autosuficiente y encerrado en sus propias reglas. Existen, además, otros factores como, por ejemplo, los socio-históricos, pero para ello debemos revisar la siguiente corriente: la historicista, también denominada nueva filosofía de la ciencia.

\section{La metateoría estructuralista}

La concepción estructuralista ${ }^{23}$ de la teoría - también denominada sintáctica - es un desarrollo específico y muy reciente producido especialmente por J. Sneed, discípulo de P. Suppes. Según Díez y Lorenzano, el estructuralismo metateórico

es una de las principales escuelas actuales en filosofía de la ciencia y la que más atención ha dedicado al análisis y reconstrucción de teorías científicas particulares y la que mayores frutos ha dado en la clarificación de los problemas conceptuales y en la explicitación de los supuestos fundamentales de teorías científicas concretas. (2002, p. 55)

Esta concepción usa el término estructura según el significado puesto en juego por la lógica de conjuntos y no debe confundirse con el significado que diversas corrientes antropológicas y lingüísti-

23 Para este apartado nos basamos casi exclusivamente en Díez y Moulines (1997, pp. 351 y ss.) y Díez y Lorenzano (2002). 
cas le atribuyen. Sneed reconoce varias herencias que configuran la tradición metateórica estructuralista (2002, p. 58): de Carnap, recupera el rigor descriptivo y el uso de instrumentos formales de análisis; de los historicistas, especialmente de Lakatos, asume, en primer lugar, que la teoría no es un conjunto de axiomas y enunciados ya que se trata de una entidad estructuralmente compleja y dinámica compuesta de un núcleo inmutable y un cinturón en transformación; en segundo lugar, retoma la identificación de dos niveles de conceptualización: el teórico y el empírico. De Kuhn, asume que la identidad de la teoría está conformada por el paradigma expresado por medio de leyes o generalizaciones simbólicas y las aplicaciones (o ejemplares). De Suppes, recoge la tesis semanticista básica según la cual la teoría es un conjunto de modelos antes que un conjunto de proposiciones y afirmaciones. Por tanto, es la lógica de conjuntos el instrumento formal de análisis, resultando inadecuados los métodos proposicionales o sintácticos cuyo objeto de control son las proposiciones o afirmaciones.

Para el estructuralismo el modelo es "un sistema real que puede ser descrito mediante un cierto lenguaje formal; es decir, el modelo no sería lo que representa un sistema real, sino aquello-que-esrepresentado por un cierto conjunto de enunciados" (2002, p. 58), de tal manera que se trata de: 1 . un conjunto formado por una serie de conjuntos (dominios o entidades contenidas en la estructura); y 2. por una serie de relaciones (Zamora Bonilla, 2001, tema vii). Por lo tanto, no debemos atribuir al término un referente necesariamente real; se trata, para esta concepción, de modelos matematizables o altamente formalizables y expresados mediante fórmulas lógicas de exclusión, inclusión, equivalencia, etc.

Sneed distingue tres dimensiones básicas para describir las teorías que conforman los puntos fundamentales de nuestra siguiente 
explicación: 1. la sincrónica (los elementos intrateóricos), 2. las relaciones interteóricas y 3. la dimensión diacrónica (las transformaciones de la teoría a lo largo del tiempo); al mismo tiempo, el análisis integrado según estas tres dimensiones explica las rupturas de la concepción estructuralista con respecto a otras, en especial con aquellas centradas exclusivamente en los elementos sincrónicos y con las que restringen el análisis solo a los elementos susceptibles de análisis formal. A continuación, desarrollaremos la metateoría estructuralista según cada una de las dimensiones propuestas por Sneed, siguiendo paso a paso a Díez y Lorenzano (2002).

\section{La estructura sincrónica de una teoría}

El corte sincrónico de una teoría es la imagen congelada en un momento de su evolución (un fotograma), según la imagen de un entramado en red (red teórica) que articula elementos estratificados según diversos grados de especificidad (2002, p. 359). Los elementos teóricos son los constituyentes de la red teórica y se consideran la expresión mínima de una teoría, de tal manera que

la parte formal global de la teoría-red queda expresada por el conjunto de las partes formales de los elementos constituyentes; su parte aplicativa global por el conjunto de las partes aplicativas de sus constituyentes. A estos elementos constituyentes se les denomina elementos teóricos. La parte formal de los elementos teóricos se denomina núcleo y su parte aplicativa dominio de aplicaciones pretendidas (propuestas o intencionales). (pp. 59-60)

Por lo tanto, los elementos teóricos se componen de una parte formal o núcleo $(K)$ y otra parte aplicativa o de aplicaciones pretendidas $(I)$, de tal manera que el conjunto se expresa $\mathrm{T}=(\mathrm{K}, \mathrm{I})$. Veamos, entonces, cuáles son los constituyentes del núcleo y las aplicaciones. 
132

\section{Componentes de la parte formal de una teoría:}

el núcleo $K=(M p, M, G C, t)$

El núcleo $(K)$ es la parte formal de la teoría, es decir, las condiciones o leyes que, según la teoría, rigen la realidad a la que se refiere, pero expresadas no en términos lingüísticos (propio del modelo axiomático), sino según la lógica modelo-teórica de conjuntos.

a. Los modelos de la teoría. El núcleo $K$ incluye modelos potenciales $(M p)$, las estructuras o entidades que pueden ser modelos de la teoría (que pudieran satisfacer las leyes). El conjunto de estos modelos expresa el aparato conceptual de la teoría; y los modelos actuales $(M)$, restringidos a aquellos que en efecto son modelos de la teoría (que de hecho satisfacen las leyes).

Zamora Bonilla (2001, tema vii) define con precisión a $M p$ y $M$ de la siguiente manera:

1. $M$ se define por una serie de axiomas (condiciones que un modelo debe cumplir para pertenecer a dicha clase), entre los que se distinguen especialmente las "tipificaciones" (indicaciones del tipo lógico de cada concepto que intervienen en los modelos, especialmente las funciones), las "caracterizaciones" (indican la estructura matemática básica de esas funciones), las "leyes fundamentales" (condiciones que establecen una relación de dependencia entre todos los conceptos del modelo) y las "leyes especiales" (condiciones que son válidas solo en algunos conjuntos de modelos de la teoría, pero no en todos ellos)" (tema vii).

2. Mp es el conjunto de las estructuras que satisfacen la estructura formal básica de los modelos de una teoría (esto es, sus tipificaciones y caracterizaciones, pero no necesariamente su ley fundamental). 
b. Las condiciones de ligadura. El núcleo Kincluye, además, las condiciones de ligadura o constraints $(G C)$ o bien las condiciones para los modelos que no derivan necesariamente de las leyes, sino de un conjunto de modelos. Así, se determinará la característica de una partícula no solo por las leyes que rigen un solo modelo, sino por la suma de los modelos bajo los cuales la partícula en cuestión es analizada. Las características de la partícula serán definidas entonces por intersección o adición conjuntista de los modelos. Las ligaduras son de dos clases: de identidad o de aditividad.

c. La teoricidad. El último elemento del núcleo es la teoricidad $(t)$ o bien la relación de un término o un concepto con respecto a la teoría. Así, un concepto no es teórico de por sí, sino que su teoricidad es proporcionada por una teoría dada que lo constituye, de tal modo "que un concepto es T-teórico si es un concepto propio de la teoría T, introducido por ella, y es T-no teórico si es un concepto previamente disponible a T" (Díez y Lorenzano, 2002, p. 62). El carácter t-teórico es dependiente de la teoría; en tanto el t-no teórico es independiente de ella y no presupone la validez de las leyes de la teoría.

La formulación de si un concepto es teórico o no se establece por un procedimiento de determinación que depende de la teoría (determino la masa de un cuerpo a partir de la teoría de la gravedad) o es independiente de la teoría (determino la masa usando procedimientos ópticos o procedentes de otro entorno teórico como, por ejemplo, la cinemática).

\section{Componentes de la parte aplicativa de las teorías:} las aplicaciones intencionales

$$
\mathrm{I}=(M p p)
$$

Las aplicaciones intencionales son la dimensión o la base empírica de las teorías o el conjunto de sistemas reales a los que se quie- 
134

re aplicar la teoría o la red teórica, y su conjunto se expresa como $I$. En lenguaje kuhniano, se trataría de los ejemplares.

a. Las pretensiones (los sistemas reales) de una teoría se individualizan y describen mediante un vocabulario previo a $T$ ( $t$-no teórico) usando, por ejemplo, para el sistema del péndulo términos previos o externos a la mecánica clásica, como posición y tiempo (describen trayectorias no en términos de masa sino relativos a la cinemática). Todos los datos están cargados de teoría, pero no todos de la teoría para la que son datos, es decir, algunos datos devienen de teorías previas o antecedentes. Cada aplicación pretendida es, entonces, un modelo parcial $(M p p)$, distinto al modelo potencial $(M p)$ o actual $(M)$, que pretende satisfacer en su totalidad la teoría, en tanto que $M p p$ por ser una realidad empírica no estaría en condiciones de lograrlo. Con relación a $M$ y $M p, M p p$ resulta de suprimir las relaciones correspondientes a los conceptos teóricos. Si como afirma Moulines (2002, p. $101)$, $I$ es un subconjunto de $M p p$, entonces podemos definir a $K$ como la especificación de los tres conjuntos $M p p, M p$ y $M$.

b. La determinación de $I$ (las aplicaciones intencionales) está guiada, además, por elementos pragmáticos, es decir, que responden a la intencionalidad de los usuarios que pretenden que las leyes se cumplan en esos y otros sistemas de acuerdo a sus expectativas e intereses.

Si unimos estas dos dimensiones tenemos que Teoría (T) se expresa según la siguiente fórmula: $T=(K, I)$ o bien $T=[K(M p, M$, $G C, t)+I(M p p)]$. Una vez entendidos los elementos que conforman la teoría, recapitulamos que el elemento teórico es una teoría en sentido mínimo y, según hemos explicado,

está constituido por (1) una parte formal, que expresa los recursos conceptuales a diferentes niveles y las constricciones-leyes que 
según la teoría rigen su ámbito de estudio, y (2) una parte aplicativa, que especifica en términos no teóricos respecto de la teoría los sistemas empíricos a los que una teoría pretende aplicarse, de los que pretende que son regidos por sus constricciones-leyes. Así, un elemento teórico $\mathrm{T}$ se identifica con el par formado por el núcleo $\mathrm{K}$, la parte formal, y el dominio de aplicaciones I, la parte aplicativa: $\mathrm{T}$ $=(\mathrm{K}, \mathrm{I})$. (Díez y Lorenzano, 2002, p. 65)

\section{Las aserciones empíricas}

La aserción empírica es lo que la teoría afirma, es decir, que existe algún conjunto de modelos $\mathrm{X}$ que satisface todos los axiomas de la teoría, y tal que la restricción de $\mathrm{X}$ a los términos no teóricos es idéntica a I; o dicho de otra manera, la aserción empírica de la teoría consiste en decir que I es subsumible dentro de un conjunto de modelos que satisfacen los axiomas de la teoría. (Zamora Bonilla, 2001, tema vii)

Según Moulines (2002, p. 100), la aserción empírica central es un enunciado que pone a prueba la teoría en un dominio dado de la realidad y para toda teoría empírica viable tal aserción debería ser falsa en el sentido de que, si bien, "ninguna teoría logra nunca ser aplicada con toda exactitud a su dominio de aplicaciones propuestas" (p. 100), la aserción empírica posee un carácter aproximativo determinado por un conjunto de aproximaciones admisibles.

\section{Las redes teóricas}

El concepto de red teórica es el que expresa de manera más rica y compleja la estructura sincrónica o estática de las relaciones intrateóricas y traduce en lenguaje formal los paradigmas o matrices disciplinares de Kuhn y los programas de investigación de Lakatos en algún momento de su evolución. "Una red teórica es un conjunto 
de elementos teóricos conectados mediante la relación de especialización" (Díez y Lorenzano, 2002, p. 69), según diversos estratos o niveles de concreción o especificidad cada vez más restrictivos hasta conformar las "ramas" de la estructura arbórea conformadas por elementos que concretan o especifican la red-teoría.

Así,

un elemento teórico $\mathrm{T}$ es especialización de otro T’ si T impone constricciones adicionales a las de T'. Ello supone que: (1) los conjuntos de modelos parciales y potenciales de ambos coinciden, e. e. su aparato conceptual es el mismo; (2) los conjuntos de modelos actuales y condiciones de ligadura de $\mathrm{T}$ están incluidos en los de T', pues algunos modelos de T' no satisfarán las constricciones adicionales que añade $\mathrm{T}$; (3) el dominio de aplicaciones pretendidas de T está incluido en el de T’, esto es, el elemento más específico se pretende aplicar a algunas aplicaciones del más general. (pp. 68-69)

\section{Relaciones diacrónicas de las teorías}

La teoría no es una realidad estática y parte de su explicación consiste en desplegar las evoluciones teóricas que le son propias, pues el concepto de red teórica no basta para acceder a la estructura de la teoría en toda su complejidad. Es necesario, además, determinar la persistencia de las teorías a pesar de las versiones que la extienden en el tiempo, aspecto en el cual el estructuralismo asume las nociones de ciencia normal de Kuhn y programas de investigación de Lakatos, precisándolas con el lenguaje formal que lo caracteriza.

El concepto que abre tal dimensión es el de evolución teórica, aún más complejo que el de red teórica pues lo incluye: "la evolución teórica es una determinada sucesión de redes teóricas en las que se conservan determinados elementos constantes a lo largo de toda la sucesión" (Díez y Lorenzano, 2002, p. 69). Los elementos que in- 
tervienen para determinar las partes esenciales y accidentales de una teoría son de índole pragmática, principalmente la comunidad de científicos y los períodos históricos. Si la teoría-red es el fotograma, la evolución teórica es la película entera.

\section{Relaciones interteóricas}

Siguiendo la línea progresiva en procura de mayor amplitud y complejidad analíticas cada vez, no basta determinar las relaciones intrateóricas (los elementos sincrónicos) y su evolución en el tiempo (los aspectos diacrónicos). Es necesario precisar el entorno teórico, es decir, la relación de los elementos teóricos, de las teorías-red y de las evoluciones teóricas con otras teorías. Tales relaciones no se establecen a partir de los conjuntos de enunciados, sino del conjunto de modelos de teorías diferentes. Estas relaciones reciben el nombre de vínculos o links $(L)$ que constituyen el último elemento del núcleo $K$. La clase total de los vínculos se expresan con las siglas $G L$.

En este punto, el análisis interteórico recupera la teoricidad de los elementos no teóricos (prestados de otras teorías) de una teoría $T$, definidos por fuera de su aparato conceptual $(M p)$, al identificar sus vínculos con el aparato conceptual $(M p)$ de la teoría de la cual depende su teoricidad ( $T$ ). Es decir: se identifica la fuente teórica de los elementos teóricamente independientes (o no teóricos) de una teoría. Así, algunos elementos que no son teóricos para una teoría lo son para otra.

Las relaciones interteóricas son de dos tipos: de reducción y equivalencia, las cuales no serán explicadas aquí.

Los vínculos $(G L)$ completan el último elemento del núcleo $K$ de una teoría científica, de tal modo que la serie completa que articula sus constituyentes queda como sigue: $\mathrm{K}=(M p, M, M p p, G C, G L)$. 


\section{Los elementos teóricos según las concepciones semánticas}

La familia semántica reúne una serie de propuestas que irrumpieron en los años $70 \mathrm{y}$, sin lugar a dudas, constituye el aporte metateórico más rico y significativo por dos razones fundamentales. En primer lugar, porque supera tanto el extremo rigor lógico-sintáctico propio de la corriente axiomática cuanto la imprecisión lógica de las corrientes historicistas ${ }^{24} \mathrm{y}$ en segundo lugar, porque incluye la categoría de sentido y significado, irrelevante para la corriente axiomática, en el centro de su edificio argumental. Por tanto, las metateorías que emergen de las concepciones semánticas revisten especial importancia para las ciencias sociales.

Esta familia metateórica recibe el calificativo de semántica porque supone que toda teoría es un instrumento para interpretar o traducirsimbólicamente una realidad, un problema o un sistema por medio de modelos que los sustituyen, según algunos, en términos lógicos y conceptuales; según otros, también por medio de una realidad perceptible que posee la capacidad de explicar otras realidades y que, a la vez, incluye todas las relaciones lógicas de la teoría. Al concebir la teoría como sustitución simbólica de la realidad a fin de entenderla e interpretarla, el concepto clave y articulador de las corrientes semánticas es el de modelo, tomado en cuenta ya por la propuesta historicista de Kuhn (cfr. supra, los conceptos kuhnianos de modelo y ejemplar como elementos de la teoría) y anticipado de alguna manera por Popper al concebir las teorías como simplificaciones de la realidad.

A continuación, revisaremos los puntos fundamentales de esta corriente de la mano de sus principales autores pertenecientes, en su mayoría, a la Universidad de Stanford, como Patrick Suppes, Ernest

24 Para el desarrollo de este apartado nos basamos fundamentalmente en Díez y Moulines (1997, pp. 327 y ss.), además, en Van Fraassen (1980) y Pérez Ransanz (2000). 
Adams, Ronald Giere y Bas van Fraassen, entre otros que han dado vida a esta visión tan reciente de la mano de fuentes secundarias ${ }^{25}$, con excepción de van Fraassen (1996).

\section{Teoría y modelo. Distinciones y relaciones}

La visión semántica asume de manera muy particular la concepción modélica, lo cual implica que las teorías no constituyen, primariamente, clases de axiomas o clases de enunciados. Las teorías, aunque los incluye son realidades que no se reducen a sus elementos lingüísticos o lógicos. El cambio de perspectiva que propicia la concepción modélica consiste en que toda teoría es una clase o un conjunto de modelos (esquemas) que se aplican a ciertos dominios de la realidad (Díez y Moulines, 1997, p. 328). Al enfatizar el carácter modélico de la teoría sobre el entramado de axiomas y enunciados, la concepción semántica pone de manifiesto que el objetivo de la teoría es ofrecer esquemas para interpretar y apropiarse de la realidad. Por lo tanto, para esta corriente "una teoría consiste en un conjunto de modelos, caracterizados por una 'definición teórica', más una aserción empírica ('hipótesis teórica') acerca de la relación entre ciertos tipos de sistemas reales y los modelos de la teoría" (Pérez Ransanz, 2000, p. 112). La relación teoría-modelo da lugar a una serie de implicaciones fundamentales que exponemos a continuación:

a. Mediante el modelo (esquema que representa la realidad), la función de la teoría es identificar una clase de datos, fenómenos o experiencias en un determinado ámbito de la realidad. Así, para la corriente semántica, de acuerdo con Van Fraassen, la teoría es una estrategia de análisis y de investigación (2000,

25 Para el desarrollo de este apartado nos basamos fundamentalmente en Díez y Moulines (1997, pp. 327 y ss.) y Pérez Ransanz (2000). 
p. 109) cuyo criterio de evaluación consiste en la productividad descriptiva e informativa respecto a la realidad.

b. La noción de modelo asume que la teoría "se aplica bien" a la realidad, a los sistemas a explicar, que los sistemas empíricos se comportan de "ese modo". "Que las leyes definen una serie de modelos significa solo que las leyes determinan qué entidades son las que se comportan de acuerdo con las teorías" (Díez y Moulines, 1997, p. 331).

c. Tanto el modelo como los fenómenos a los que se refieren son los elementos esenciales de la teoría y la relación entre ambos se expresa mediante una proposición que constituye la aserción empírica de la teoría.

d. Las teorías, como conjuntos de modelos, no son ni verdaderas ni falsas. Son aplicables o no aplicables, adecuadas o inadecuadas, explicativas o poco explicativas, de tal manera que el carácter de verdad o falsedad se restringe a la adecuación o inadecuación empírica respecto a los hechos que caen bajo el dominio de la teoría, de tal modo que las aserciones empíricas derivadas sí podrán ser verdaderas o falsas. Las teorías no son falsables primariamente, pero sí derivativamente en el sentido de que, si la aserción (la supuesta adecuación empírica) es falsa, la teoría queda falsada. En tal sentido, esta posición contesta la pretendida infalsabilidad del núcleo teórico tal como pretende Lakatos, según el cual la falsación afecta solo el cinturón protector de hipótesis específicas. Los hechos que no caben en el modelo crean una incomodidad que obliga a expandir o cambiar la teoría.

e. La opción modélica pretende superar la sintaxis propia de la corriente axiomática a favor de la matemática conjuntista como procedimiento y regla para establecer la extensión de los predicados y el modo de relación entre teorías y sistemas. Según la matemática conjuntista, toda aserción da cuenta de 
una forma de relación, fuerte o débil, entre modelo y fenómeno: el sistema fenoménico puede representar un caso idéntico al modelo, aproximado o subsumido en él.

f. El punto de vista semántico es interesante también porque incluye la relación entre teorías, a partir de los conjuntos y en términos de inclusión y traducibilidad. Así, es posible afirmar que una teoría incluye otras, o que representa una de carácter más general o es más progresiva (Dalla Chiara, 2001, p. 241). Al postular que toda teoría interesante no es autosuficiente para explicar un dominio y que es menester acudir a otra para amplificar su potencia explicativa (p. 241), este enfoque supera la inconmensurabilidad entre teorías afirmada por Kuhn y encamina las preferencias en favor de la diversidad complementaria y la cohabitación de teorías, principio que expresa muy bien la práctica cotidiana de las ciencias sociales.

Figura 10

Relaciones del modelo con los elementos empíricos

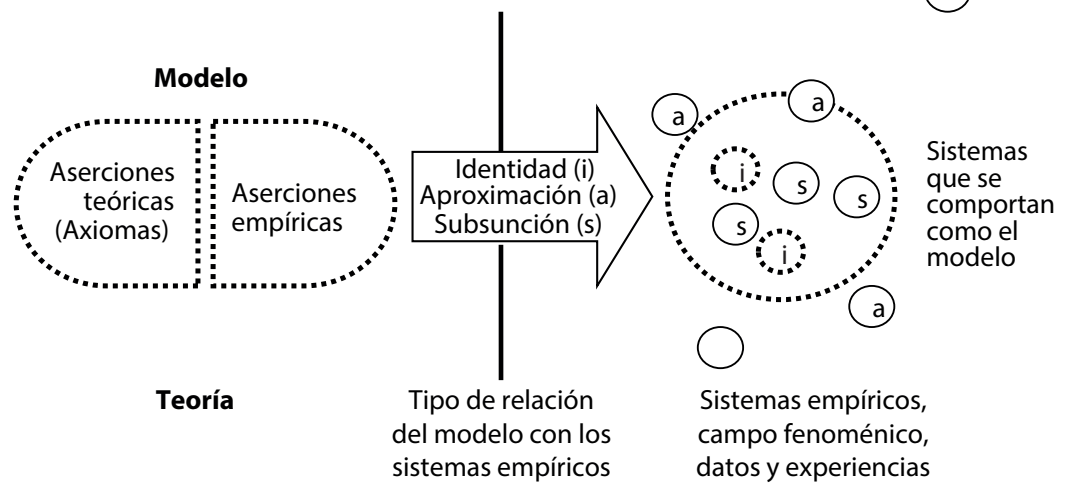

Elaboración de los autores a partir de Díez y Moulines (1997), Van Fraassen (1980) y Pérez Ransanz (2000). 
La Figura 10 permite apreciar los elementos de la teoría y sus relaciones según la concepción semántica modelística. Pero algunos autores de la corriente semántica proponen variantes al esquema básico del cuadro anterior. La primera es la de Ernest Adams (Díez y Moulines, 1997, pp. 340 y ss.), según la cual es posible considerar un número limitado de sistemas reales como modelos pretendidos para otras realidades; es decir, el modelo es un caso ejemplar de la realidad cuyas relaciones y características poseen el potencial para explicar otros casos reales por analogía. Así, los sistemas Tierra-Luna o Sol-planetas, por ejemplo, son sistemas reales que se constituyen en modelos pretendidos de la física newtoniana (de su teoría) para entender otros sistemas planeta-lunas, como el caso de Júpiter y sus lunas. Desde este punto de vista, toda teoría consta de un aspecto formal (los predicados conjuntistas y la extensión de dicho predicado a los sistemas que le corresponden) y un aspecto explicativo (el conjunto de modelos pretendidos que sirven para explicar otros sistemas). En la selección de los sistemas reales que corresponden al modelo ejemplar, juega un papel importante la comunidad de científicos y su producción científica.

Una segunda variante es la que proporciona Ronald Giere para quien el modelo teórico es "un mundo imaginado" (no un sistema real), a la manera de mapa de la realidad cuyo componente más importante es la estructura; es mediante esta que un mapa rinde su información y se relaciona con la realidad sin copiar lo que representa, sino que

representa reproduciendo, a una escala mucho menor, las relaciones estructurales existentes entre elementos del territorio. Las líneas de un mapa se relacionan estructuralmente entre sí de tal manera que representan las relaciones entre las partes del propio territorio. En ambos casos, la estructura de la representación casa con la estructura 
de aquello que representa. Podemos expresar esto diciendo que ambos son "estructuralmente isomórficos". (Lynch, 2005, p. 108)

Una realidad es susceptible de ser representada por medio de estructuras diferentes tal como ocurre, por ejemplo, con una misma canción grabada según formatos estructuralmente tan diversos como el LP, el CD o el MP3 (p. 108). Por último, la estructura mantiene una relación de realismo causal respecto a la realidad pues un "mapa no sería como es si el territorio no fuese como es" (p. 110). Según Giere, la hipótesis teórica es el tipo de aserción que corresponde a la teoría entendida como mapa de la realidad y se trata de una entidad lingüística de carácter proposicional que afirma cierto tipo de relación entre un modelo y un sistema real, relación plausible de ser verdadera o falsa. Resumimos en algunas proposiciones fundamentales las características de la hipótesis teórica (Díez y Moulines, 1997, p. 348):

a. En la hipótesis, la relación entre modelo y sistema no es de identidad sino de semejanza y similitud, caracteres que deben ser explicitados de tal manera que "tal sistema real identificable es similar al modelo designado en los aspectos y grados indicados". Al mismo tiempo, no todos los aspectos del sistema real se deben reflejar en el modelo.

b. Los enunciados que formulan la teoría no están en conexión directa con el mundo real, sino que se conectan indirectamente con el mundo por medio de los modelos.

En razón de ello, la concepción modélica de Giere provoca que las teorías científicas no sean entidades bien definidas. En tanto constructos sociales, la comunidad de científicos interviene para identificar los modelos y los sistemas de referencia pertinentes según un esquema flexible e incluyente que hace posible adoptar, como vimos, varios modelos para comprender un mismo sistema, de la mis- 
144

ma manera que podemos circular por Quito con dos mapas diferentes, pero nunca con un mapa de Guayaquil.

\section{Semántica, ontología y epistemología de los modelos. Su relación con las teorías}

La Enciclopedia de Stanford (2020) sistematiza el alcance actual sobre la concepción y uso los modelos ${ }^{26}$ y da cuenta de su creciente importancia en contextos científicos, tal como podemos corroborar en la práctica académica cuando oímos mencionar, cada vez con mayor frecuencia, términos como "modelar", "modelización", "construir" o "aplicar modelos". También se ha vuelto usual, sobre todo en las ciencias tecnológicas, la referencia a "modelos computacionales", "modelos explicativos", "modelos teóricos", "modelos exploratorios", "modelos matemáticos”, etc., hasta conformar la terminología de rigor. Hoy día, tales nociones forman parte del vocabulario normal de la ciencia, pero reclaman respuestas pendientes a preguntas de orden semántico (cómo representan los modelos), ontológico (qué tipo de cosas son los modelos), y epistémicos (de qué manera los modelos permiten conocer) que no son poseídas con la misma naturalidad que cabría suponer por el uso de los términos. El Cuadro 1 ofrece un extracto de las respuestas de la Enciclopedia a estos interrogantes, desarrollando con mayor pausa aquellos aspectos que convocan el eje de la metateoría.

26 Ver Models in Science (2006). 


\section{CUADRO 1: LOS MODELOS EN LA CIENCIA ${ }^{27}$}

\section{Aspectos semánticos de los modelos: ¿cómo representan la realidad?}

La dimensión semántica define los modelos como recursos simbólicos que representan de cierta manera un ámbito selectivo de la realidad (sustituyen la realidad), es decir, aquello que se quiere comprender. Este ámbito de la realidad que se quiere representar se denomina "sistema objetivo del modelo" o también "sistema de destino". La Enciclopedia, entre otros, proporciona el ejemplo del modelo de economía abierta de Mundell-Fleming o el modelo a escala de un puente (el más simple y fácil de entender). Tipos de modelos de representación son los que se describen a continuación y, aunque puedan compartir pertenencia con otras categorías, sus diferencias responden a formas específicas de representación.

Modelos a escala: son copias reducidas o ampliadas de sus sistemas de destino, como las maquetas de edificios a escala reducida para simular en laboratorio su sismorresistencia. El comportamiento de esta forma de representación nunca será igual al del sistema de destino y ello solicitará correcciones y tabulaciones que anticipan la relación no del todo lineal entre lo representado y el modelo.

Modelos analógicos: se basan, valga la redundancia, en la analogía, una figura literaria y un recurso lingüístico de gran valor heurístico que comprende una realidad sobre la similitud del comportamiento o con (entre) propiedades compartidas con otra realidad. Entre otros ejemplos, podemos citar el modelo hidráulico de un sistema económico o el modelo del agujero negro. El ejemplo epistémico más frecuente es

27 Para la síntesis de la Stanford Encyclopedia of Philosophy se obvian las numerosas y densas referencias al estado actual de la discusión y a los aportes críticos a cada uno de los temas. Asimismo, y por razones obvias, la síntesis no recoge la enorme riqueza de ejemplos. 
aquel que comprende analógicamente el pensamiento con la visión; y la comprensión, con la iluminación. No obstante, el uso de la analogía es más complejo y se expresa también en ecuaciones matemáticas compartidas.

Modelos idealizados: son aquellos que proceden vía simplificación o distorsión deliberadas y controladas del sistema de destino para afrontar la comprensión de sistemas demasiado complejos. Se conocen dos tipos de idealizaciones: las aristotélicas, que simplifican despojando el sistema de destino de propiedades no relevantes para el análisis y poder concentrarse en lo esencial; y las galileas, que distorsionan deliberadamente un sistema de destino como, por ejemplo, cuando se representa el movimiento de masas despojadas de fricción, o cuando se postula el movimiento perpetuo a partir de un péndulo despojado de la resistencia de sus elementos concretos. También cuando se explica la conducta económica a partir de un sujeto omnisciente y racional. Un concepto relacionado con la idealización es el de aproximación, que marca la relación de un modelo a otro por criterio de cercanía y no tanto (aunque no lo excluye) porque exista relación entre sus elementos.

Modelos de juguete: son modelos extremadamente simplificados y distorsionados de los sistemas objetivos, como si fueran caricaturas y representan una cantidad muy limitada de caracteres de los sistemas objetivos. El procedimiento es aislar un número determinado de características y distorsionarlas al extremo. La Enciclopedia cuestiona el valor predictivo de tales modelos debido a la sobresimplificación de la realidad ${ }^{28}$. Los modelos mínimos son representaciones muy simplificadas de los sistemas de destino y, por ello, están relacionados con los modelos de juguete. No necesariamente se trata de representaciones del sistema de destino.

28 En realidad, la lógica comercial obedece muchas veces a la toma de decisiones basada en la simplificación de atributos para establecer el precio de inventario de ciertos productos, aplicando un descuento anual de su valor regido por el criterio temporal respecto a su adquisición. Así, sin importar la demanda o el valor intrínseco de ciertos productos, la norma se aplica a todos por igual. 
Modelos fenomenológicos: representan propiedades observables de sus sistemas objetivos. A veces se los presenta independientemente de las teorías, sin que se deriven de ellas, aunque incorporen elementos teóricos, como leyes físicas que explican parcialmente el funcionamiento del sistema de destino. A este tipo de modelo pertenecen los modelos de un "fenómeno", entendiendo este último término como el conjunto de características relativamente estables y generales de un suceso particular de interés y al alcance de la observación de la ciencia como, por ejemplo, el comportamiento de los precios de vivienda y sus relaciones con determinadas características, el crecimiento de la población de cierto tipo de fauna y flora.

Modelos exploratorios: son de carácter dinámico y su función es la de aprender algo sobre un sistema objetivo específico o un fenómeno bajo experimento sin contar con un modelo acabado. El modelo inicial es un punto de partida para nuevas y sucesivas exploraciones, a lo largo de las cuales se modifica y refina el modelo. Por lo tanto, se debe distinguir entre modelos iniciales y modelos a medio término o término de la investigación. Este tipo de modelo es una herramienta útil para la analizar las características de una teoría.

Modelos de datos: requieren de herramientas estadísticas complejas y de una cada vez mayor capacidad de almacenamiento y procesamiento de datos obtenidos de la observación inmediata. Estos modelos se desarrollan por medio de la "reducción de datos", proceso de depuración de dos fases: a) eliminación de errores (debido a una observación defectuosa); y b) presentación ordenada de los datos. Estos modelos representan el sistema de destino a la manera de curvas delineadas por los puntos de los datos. Son importantes para la confirmación de teorías y el problema crucial consiste en la capacidad de determinar las técnicas de información adecuadas para comprender el sistema de destino. Entre otros ámbitos, se usa cada vez más en análisis de conductas de consumo, y para comprender y anticipar la expectativa de públicos de usuarios. 


\section{Aspectos ontológicos: ¿qué son los modelos?}

Los modelos deben ser entendidos como una gama heterogénea de cosas con capacidad de representar un sistema objetivo. Se trata de artefactos mentales o físicos, de objetos que representan la realidad y a la hora de describir aquellos que efectivamente usan los científicos incluyen los siguientes tipos: "objetos físicos, objetos ficticios, objetos abstractos, estructuras teóricas de conjuntos, descripciones, ecuaciones” o sus combinaciones. Cada uno representa y explica los sistemas de destino de manera diferente.

Objetos físicos: se denominan también "objetos materiales", como los modelos a escala, los que representan la estructura y secuencia del $\mathrm{ADN}$, las maquetas geofísicas.

Objetos de ficción y objetos abstractos: aunque los científicos se refieren a estos como si se tratara de objetos, estos modelos son ficticios porque existen en la mente de los investigadores, como el modelo de átomo de Bohr. Se usan objetos de ficción para imaginar realidades físicas, poblacionales o económicas ficticias, del tipo "imaginando que una población dada, en una situación dada... etc.”. El valor de estos modelos es proporcionar visiones imaginativas cargadas de valor eurístico (permiten pensar y suponer) pero plantean dificultades a la hora de establecer su conexión con la realidad y si es viable la pretensión de representar la realidad por medio de ficciones. Los objetos abstractos, a su vez, son entidades no físicas que representan un posible objeto concreto en tanto figuras del habla, del lenguaje, sin referencia en la realidad. No obstante, la discusión es vigente. Hoy, podemos comprender mejor la pandemia del coronavirus por medio de las ficciones cinematográficas que de alguna manera la anticiparon, que resultan útiles para abordar la comprensión de comportamientos colectivos ante la crisis y el aislamiento.

Estructuras teóricas: esta aproximación es propia de la visión semántica de las teorías que define los modelos como estructuras teóricas, fundamentalmente, de dos tipos: modelos interpretativos y modelos mediadores. La Enciclopedia cuestiona esta postura porque, en tanto 
estructuras teóricas, los modelos no pueden ser representativos de un sistema objetivo por las siguientes razones: muchos no se ajustan a una estructura; no es posible establecer su comportamiento ni el de sus elementos a lo largo de la investigación; su estructura no refleja relación de correspondencia con la estructura del sistema objetivo. Estos modelos se refieren, más bien, a la estructura de la teoría, no a la de un posible modelo representativo de un sistema objetivo.

Descripciones y ecuaciones: según esta forma de aproximación propia de la visión sintáctica de la teoría, "un modelo es una descripción estilizada de un sistema de destino". De esta forma confunde el modelo con la formulación particular de la teoría, con la configuración particular de sus elementos cuando, en realidad, se trata de enunciados descriptivos. El modelo, según esta vertiente, tendría un valor descriptivo pero no refleja un sistema objetivo, sino un sistema articulado de enunciados de diverso nivel sobre él. Asimismo, la descripción remite obligadamente a su forma literaria cuando el modelo se comporta de manera diversa: es un objeto que sustituye la realidad y de cuya representación objetual emanan descripciones.

La concepción del modelo como articulación de ecuaciones es otra versión que obedece a la misma lógica, tanto por su valor descriptivo cuanto porque son elementos sintácticos que describen una estructura matemática. Así, la ecuación no es un modelo porque este tiene propiedades representativas diferentes.

\section{Epistemología: funciones cognitivas de los modelos}

Los modelos son importantes en la ciencia, principalmente por su valor cognitivo porque permiten conocer y aprender mediante un "razonamiento subrogante", es decir, colocándose en lugar de la parte de la realidad o el fenómeno que se quiere comprender. De ese modo, "algunas partes importantes de la investigación científica se llevan a cabo en modelos en lugar de en la realidad misma”. 
Aprender acerca de los modelos: no hay fórmulas para aprender a construir o evaluar modelos a no ser la de aprender haciendo. En el uso y la manipulación concretas aprendemos de las propiedades y las capacidades de un modelo, no antes. Algunos tipos de modelos permiten, más que otros, aprendizajes sobre su funcionamiento y, por lo tanto, son más propensos a mejoras y rectificaciones tal como sucede con los modelos matemáticos y computacionales que ofrecen mayores posibilidades de simulación. Pero no siempre la comprensión de una realidad y la fortaleza de los modelos son directamente proporcionales a la capacidad de incorporar e interpretar datos. Es posible que se generen, de la mano de esas capacidades, distorsiones y limitaciones.

Aprender acerca de los sistemas de destino: es clave que los modelos reflejen adecuadamente los sistemas de destino según correspondencias consistentes. Los aprendizajes en tal contexto serán diversos según el tipo de representación modélica, ya que cada uno está cargado de posibilidades y límites distintos.

La explicación mediante modelos: cabe aquí preguntarse qué tipo de explicación ofrecen los modelos y las respuestas a esta pregunta están ligadas al criterio de verdad-validez de las explicaciones científicas. La pregunta básica es si lo modelos ofrecen o no acceso a explicaciones de carácter causal. En este sentido, algunos modelos ofrecen explicaciones más realistas que otros, de tal modo que el rango explicativo es muy bajo cuando se trata de modelos muy idealizados; en tanto que cuanto mayor es la correspondencia del modelo con el sistema objetivo tanto mejor su capacidad explicativa. Para otras posiciones el valor explicativo depende del carácter relevante de la explicación causal, no importa si se trata de modelos más cercanos o lejanos al sistema objetivo. Algunos, inclusive, otorgan valor explicativo a los modelos falsos que explican, aun, "debido a su falsedad".

La comprensión mediante modelos: la comprensión "es una forma particular de acceso epistémico que un científico posee para ofrecer una explicación”. Se trata de un conocimiento de carácter holístico que 
relaciona la investigación de un fenómeno con el contexto más amplio de una teoría y sus métodos o desde un modelo, poniendo en juego un ámbito de explicaciones y recursos más amplio. Los modelos juegan un papel crucial en la comprensión científica porque relacionan la tarea de explicar ese fenómeno desde la capacidad explicativa del modelo cuya capacidad comprensiva no culmina en lo que puede o no afirmar sobre su sistema objetivo, ya que abarca e incluye también el cuerpo de afirmaciones y métodos más amplio e integral que constituye ese modelo.

Síntesis de Stanford Encyclopedia of Philosophy (2006).

Con respecto a la relación entre las teorías y los modelos, la Enciclopedia plantea posiciones que van desde postular modelos como subpartes de las teorías hasta modelos independientes de las teorías, y también reconocer los modelos como mediadores entre las teorías y el mundo. Revisemos esa tipología.

Modelos como subpartes de la teoría: para entender las relaciones entre los modelos y las teorías es necesario recordar que una teoría es un conjunto de oraciones (proposiciones) expresadas en un lenguaje formal; en tanto que un modelo es una estructura que hace posible "que todas las proposiciones de una teoría sean verdaderas cuando sus símbolos se interpretan como referencia a objetos, relaciones o funciones de una estructura", de tal manera que "la estructura es un modelo de la teoría en el sentido de que es correctamente descrita por la teoría”. Otra distinción clave es la que existe en las nociones de modelo lógico y modelo representativo, de forma tal que los modelos teóricos indican que son interpretaciones de un sistema formal abstracto (modelos lógicos) y cuando leyes generales se aplican a un modelo en particular este resulta ser una interpretación (o realización) de la ley general. Por lo tanto, existen modelos lógicos que no son representativos y otros que son ambas cosas a la vez. 
Tanto para la visión sintáctica como para la visión semántica de las teorías, los modelos juegan un rol secundario respecto a las teorías. Para la visión sintáctica la teoría es un dispositivo lógico (conjunto de proposiciones articuladas en un sistema lógico axiomatizado) y hace del modelo una interpretación alternativa de un cálculo determinado que opera cálculos formales abstractos. La visión semántica, en cambio, prescinde de proposiciones organizadas según un sistema lógico axiomatizado e interpreta la teoría como familia de modelos ("un modelo es un cluster de teorías") como si se tratar de bloques de construcción de las teorías.

Modelos independientes de las teorías: ambas visiones, tanto la sintáctica como la semántica, consideran los modelos como instancias subordinadas a las teorías. No obstante, los modelos gozan de varias formas de libertad respecto a las teorías especificadas de la siguiente manera:

- Los modelos completamente independientes de la teoría: un ejemplo es el modelo Lotka-Volterra que describe la interacción entre una población de depredadores y otra de animales de presa. Ese modelo se desmarca de las teorías disponibles que explican el comportamiento de ambas poblaciones y establece suposiciones con base en ecuaciones diferenciales porque no resultaron atractivas. Cuando un modelo se construye sobre la inexistencia de una teoría relacionada con el fenómeno se llama "modelo sustituto" porque, en efecto, sustituye una teoría.

- Los modelos como medios para explorar teorías: ello ocurre cuando un modelo "es un modelo lógico de una teoría" y tiene la capacidad de desplegar sus proposiciones e inferencias. También modelos que no son lógicos son aptos para explorar teorías como aquellas que apelan a los principios del "caos". 
- Los modelos como complementos de teorías: se trata de modelos que proporcionan un referente concreto y de distinto signo a los de determinada teoría. Es el caso de una teoría cualitativa cuyo modelo le provee de medidas cuantitativas, porque la teoría está subdeterminada en determinados campos que el modelo complementa o porque existen procesos no especificados en la teoría, aunque relacionados con ella. Los modelos pueden ofrecer soluciones y aplicaciones que no derivan de las teorías per se.

- Los modelos como teorías preliminares: se trata de modelos de sondeo, de los cuales no se espera que cumplan a cabalidad su función de representación ("no instruyen más allá del propio modelo"). Se usan para probar nuevas y más complejas herramientas teóricas.

- Los modelos interpretativos: intervienen siempre que se aplica una teoría en su forma matemática general, como ocurre con las teorías físicas, de tal modo que el modelo interpreta cuando concreta los términos abstractos para describir el sistema objetivo al que representa. Ejemplo: en el contexto de la mecánica clásica, el concepto abstracto de fuerza se concreta en el concepto de gravedady, para obtener ecuaciones manejables, el modelo proporciona un escenario simplificado (planetas esféricos y homogéneos, espacio vacío), dejando a un lado la complejidad real. Así, es posible interpretar la aplicación de teorías matemáticas a objetos del mundo real.

Modelos como mediadores: los modelos constituyen instrumentos que median entre las teorías y el mundo. Las teorías no son máquinas expendedoras que proporcionan modelos y para ello es menester considerar los modelos como "agentes autónomos", tanto de las teorías cuanto de sus sistemas de destino. A veces se alimentan de teorías diferentes que trabajan colaborativamente, como sucede en el modelado climático, en el que el resultado no depende de una teoría, sino del trabajo en conjunto entre varias teorías que un modelo hace posible. 


\section{La articulación de las teorías según las corrientes historicistas}

Si el enfoque de las concepciones axiomáticas y estructurales privilegia la gramática del lenguaje lógico, las posturas generadas por la "revuelta historicista" hacen prevalecer, en cambio, los factores exógenos a las mismas teorías para explicar sus cambios, permanencia o evaluación, como la fuerza de la comunidad científica, las percepciones éticas, políticas u ontológicas de una sociedad, sus valoraciones sociales, entre otros factores que no se relacionan directamente con el despliegue de la lógica teórica. La tesis fundamental de los historicistas afirma que toda teoría consta de elementos históricos y sociales ineliminables, que son inaccesibles al análisis formal que intervienen en la evaluación de las teorías y en la preferencia de unas respecto a otras. A partir de análisis dúctiles y flexibles que privilegian los aspectos diacrónicos del ejercicio teórico, algunos filósofos de la ciencia explican el progreso científico de diversas maneras, a la vez que identifican algunos elementos de las teorías que conservan su identidad no obstante los cambios; y otros, en cambio, que cambian y se transforman en el curso del tiempo y resultan de carácter accidental y periférico.

A continuación, desarrollaremos brevemente la propuesta historicista de tres filósofos de la ciencia, casi contemporáneos y conocidos entre sí29: Thomas Kuhn (1922-1996) ${ }^{30}$, Imre Lakatos (1922-

29 Para este apartado nos basamos en el guion temático proporcionado por Díez y Moulines (1997, pp. 310 y ss.), profundizado por los siguientes textos capitales: La estructura de las revoluciones cientificas de Kuhn ([1962] 2006), La metodología de los programas de investigación cientifica de Lakatos ([1968] 1989) y El progreso y sus problemas. Hacia una teoría del crecimiento cientifico de Laudan ([1977] 1986).

30 Thomas Kuhn, estadounidense. Se graduó de físico en la Universidad de Harvard y fue un connotado filósofo e historiador de la ciencia. Ejerció la cátedra en las universidades de California (Berkeley) y de Princeton, así como en el Instituto Tecnológico de Massachusetts (MIT, por sus siglas en inglés). 
$1974)^{31}$ y Larry Laudan (1941)32. Ellos enriquecieron el vocabulario metateórico con términos como microteorías, teorías particulares o teorías rivales, postulando entre esas realidades formas de articulación más amplias expresadas en los términos macroteoría, familia teórica y redes teóricas. Ninguna de ellas se explica a sí misma sino en relación con marcos históricos más profundos e implícitos que explican no solo las relaciones sincrónicas y diacrónicas entre teorías, pues condicionan y otorgan, sobre todo, los atributos de credibilidad, legitimidad y consistencia al ejercicio de la ciencia.

Esos marcos que nuclean teorías o grupos de ellas y formas de hacer ciencia son los siguientes: paradigma (Kuhn), programas de investigación (Lakatos) y tradiciones de investigación (Laudan). En la Tabla 8 explicamos cada una de ellas anticipando similitudes y diferencias:

Tabla 8

Aspectos metateóricos de las corrientes historicistas

\begin{tabular}{|c|l|l|l|}
\hline \multirow{1}{*}{ Kuhn } & \multicolumn{3}{|c|}{ Corrientes historicistas } \\
\cline { 2 - 4 } & \multicolumn{1}{|c|}{ Lakatos } & \multicolumn{1}{|c|}{ Laudan } \\
\hline \multirow{5}{*}{ Concepto clave } & $\begin{array}{l}\text { Paradigma o matriz } \\
\text { disciplinar } \\
\text { Son excluyentes (no } \\
\text { coexisten). } \\
\text { Compromisos com- } \\
\text { partidos por la comu- } \\
\text { nidad de científicos. }\end{array}$ & $\begin{array}{l}\text { Programas de } \\
\text { investigación } \\
\text { Son coexistentes. } \\
\text { Componentes: heurís- } \\
\text { tica negativa (núcleo } \\
\text { sólido); heurística po- } \\
\text { sitiva (cómo cambiar a } \\
\text { nivel de microteorías); } \\
\text { teorías particulares. }\end{array}$ & $\begin{array}{l}\text { Tradiciones de } \\
\text { investigación } \\
\text { Pueden coexistir. } \\
\text { tidos, articulación } \\
\text { teórica, resolución de } \\
\text { problemas, desarrollo } \\
\text { histórico. }\end{array}$ \\
\hline
\end{tabular}

31 Imre Lakatos, húngaro de origen judío. Fue economista, filósofo y matemático; discípulo de Popper y catedrático de la London School of Economics.

32 Larry Laudan, estadounidense. Doctor en Filosofía por la Universidad de Princeton; catedrático de varias universidades, entre ellas, Pittsburgh e Illinois. Actualmente es investigador de la Universidad Nacional de México. 


\begin{tabular}{|c|c|c|c|}
\hline & \multicolumn{3}{|c|}{ Corrientes historicistas } \\
\hline & Kuhn & Lakatos & Laudan \\
\hline $\begin{array}{l}\text { Concepción } \\
\text { de ciencia }\end{array}$ & $\begin{array}{l}\text { Dos ciencias: ciencia } \\
\text { normal y ciencia } \\
\text { revolucionaria. } \\
\text { El paso de una a otra } \\
\text { se da por una crisis } \\
\text { paradigmática. }\end{array}$ & $\begin{array}{l}\text { Dos formas de ejerci- } \\
\text { cio: heurística positiva } \\
\text { (ajusta las teorías) y } \\
\text { heurística negativa } \\
\text { (lo que no se puede } \\
\text { cambiar). }\end{array}$ & $\begin{array}{l}\text { La ciencia es una sola } \\
\text { pero la rivalidad de las } \\
\text { teorías para solucio- } \\
\text { nar problemas empí- } \\
\text { ricos y conceptuales es } \\
\text { un rasgo permanente. }\end{array}$ \\
\hline $\begin{array}{l}\text { Factor explica- } \\
\text { tivo del cam- } \\
\text { bio teórico }\end{array}$ & $\begin{array}{l}\text { El cambio es siempre } \\
\text { paradigmático y se da } \\
\text { por razones externas } \\
\text { relacionadas con las } \\
\text { demandas de la co- } \\
\text { munidad científica. }\end{array}$ & $\begin{array}{l}\text { Cambio por contenido: } \\
\text { progresión empírica } \\
\text { (más importante): apa- } \\
\text { rece una teoría con ma- } \\
\text { yor potencial empírico } \\
\text { predictivo y explicativo } \\
\text { (más importante). } \\
\text { Progresión teórica } \\
\text { (menos importante): } \\
\text { la anterior se inserta } \\
\text { en la nueva. }\end{array}$ & $\begin{array}{l}\text { Cambio por grado de } \\
\text { eficacia para resolver } \\
\text { problemas empíricos } \\
\text { y conceptuales. } \\
\text { La resolución de } \\
\text { problemas concep- } \\
\text { tuales explican mejor } \\
\text { el crecimiento cien- } \\
\text { tífico y los cambios } \\
\text { teóricos. }\end{array}$ \\
\hline $\begin{array}{l}\text { Relación entre } \\
\text { paradigmas }\end{array}$ & $\begin{array}{l}\text { Inconmensurabilidad } \\
\text { entre uno y otro pa- } \\
\text { radigma; radicalidad } \\
\text { de los cambios. }\end{array}$ & $\begin{array}{l}\text { Los cambios equivalen } \\
\text { a progreso empírico. } \\
\text { Son progresivos y } \\
\text { acumulativos pero } \\
\text { en ocasiones son } \\
\text { cualitativos. }\end{array}$ & $\begin{array}{l}\text { Cambios progresivos } \\
\text { y acumulativos pero } \\
\text { no necesariamente li- } \\
\text { neales. Cohabitación } \\
\text { entre teorías rivales. }\end{array}$ \\
\hline $\begin{array}{l}\text { Elementos } \\
\text { de las teorías }\end{array}$ & $\begin{array}{l}\text { Generalizaciones } \\
\text { simbólicas, modelos, } \\
\text { valores y ejemplares. }\end{array}$ & $\begin{array}{l}\text { Dos tipos de teorías: } \\
\text { microteorías, serie de } \\
\text { teorías. }\end{array}$ & $\begin{array}{l}\text { Compromisos } \\
\text { metafísicos. } \\
\text { Normas epistémicas y } \\
\text { metodológicas. } \\
\text { Componentes de } \\
\text { la teoría: supuestos } \\
\text { axiomáticos, pre- } \\
\text { dicciones empíri- } \\
\text { cas, explicaciones } \\
\text { fenoménicas. } \\
\text { Microteorías y } \\
\text { macroteorías }\end{array}$ \\
\hline
\end{tabular}

Elaboración de los autores a partir de Díez y Moulines (1997, pp. 310 y ss.). 


\section{El paradigma o matriz disciplinar de Kuhn}

Thomas Kuhn, en su célebre ensayo La estructura de las revoluciones cientificas (1962), distingue dos modos fundamentales de hacer ciencia: la ciencia normal y la ciencia revolucionaria. En el primero, la ciencia se desarrolla a partir de presupuestos compartidos por una comunidad científica, presentes en los canales habituales de enseñanza y difusión disciplinaria. La tarea normal, en este contexto, consiste en la resolución de problemas, la cual exige un permanente ajuste en la relación teoría-experiencia sin necesidad de discutir los fundamentos de la ciencia. Cuando se perciben anomalías y casos que no encajan se produce una crisis que provoca la discusión de los fundamentos, se descubren otros supuestos que permiten explicar las anomalías y ser adoptados por la comunidad científica al punto de proliferar alternativas y nuevos enfoques rivales. Ocurre, entonces, una revolución científica, el segundo modo de hacer ciencia. Así, el paso de uno a otro no es provocado por las inconsistencias lógicas, sino por un "desplazamiento de confianza" creado por problemas que no logra resolver o por la intervención de factores como las demandas sociales.

La realización subyacente que impulsa la producción teórica es, según Kuhn, el paradigma, respecto al cual propone una serie de definiciones de progresiva complejidad, mejor basadas en sus rasgos dinámicos (cómo funciona) que en definiciones esenciales (qué es). En primer lugar, afirma que se trata de una realidad histórica, de "realizaciones científicas universalmente reconocidas que, durante cierto tiempo, proporcionan modelos de problemas y soluciones a una comunidad científica" (2006, p. 13). Estas realizaciones están estrechamente relacionadas con la ciencia normal y comparten dos ventajas: la de convocar grupos de científicos en un tipo de ejercicio no basado en la competencia; y la incompletud respecto a la solución 
158

de problemas pendientes. Con referencia a esas realizaciones, Kuhn afirma que:

Su logro carecía suficientemente de precedentes como para haber podido atraer a un grupo duradero de partidarios, alejándolos de los aspectos de competencia de la actividad científica. Simultáneamente, eran lo bastante incompletas para dejar muchos problemas para ser resueltos por el redelimitado grupo de científicos. Voy a llamar, de ahora en adelante, a las realizaciones que comparten esas dos características, "paradigmas", término que se relaciona estrechamente con "ciencia normal". (2006, pp. 33-34)

De manera más detallada, especifica el paradigma, según el significado dominante, como el conjunto de compromisos y supuestos compartidos por un grupo científico; según el significado alternativo, asumido por el autor, se trata también de un ejemplo o caso de algo que hace de modelo para comprender otros casos de lo mismo. Su estudio concluye describiendo otro tipo de doble sentido según el cual debe ser entendido el concepto de paradigma:

Por una parte, significa toda la constelación de creencias, valores, técnicas, etc., que comparten los miembros de una comunidad dada. Por otra parte, denota una especie de elemento de tal constelación, las concretas soluciones de problemas que, empleadas como modelos o ejemplos, pueden remplazar reglas explícitas como base de la solución de los restantes problemas de la ciencia normal. (p. 269)

La ciencia normal es la que se basa en un paradigma; la ciencia revolucionaria es aquella que pasa de un paradigma a otro. Pero uno de los rasgos del paradigma es constituirse en fuente de coherencia al actuar como garante de las teorías a las que otorga credibilidad, debido a su cobijo en la ciencia normal y no - necesariamente- en razón del cumplimiento o no de las reglas, pues la ciencia normal no está determinada por reglas. 
La ciencia normal es una actividad altamente determinada, pero no necesita estar determinada enteramente por reglas. Esta es la razón por la cual, al comienzo de este ensayo, presenté paradigmas compartidos, más que reglas, suposiciones y puntos de vista compartidos, como fuente de coherencia para las tradiciones de la investigación normal. Las reglas, según sugiero, se derivan de los paradigmas; pero estos pueden dirigir la investigación, incluso sin reglas. (p. 79)

$[\ldots]$

La ciencia normal puede determinarse en parte por medio de la inspección directa de los paradigmas, proceso que frecuentemente resulta más sencillo con la ayuda de reglas y suposiciones, pero que no depende de la formulación de estas. En realidad, la existencia de un paradigma ni siquiera debe implicar la existencia de algún conjunto completo de reglas. (p. 82)

Ningún elemento es comunicable entre las teorías de un modo de hacer ciencia con respecto a las teorías del otro. Por tanto, una de las características que atribuye a los paradigmas - y que nosotros aplicamos a las teorías — es la inconmesurabilidad o imposibilidad de comparación entre las teorías enroladas en paradigmas distintos, pues obedecen a cambios tan drásticos y radicales que impiden toda posible comparación.

Díez y Moulines (1997, pp. 313-318) describen los siguientes elementos que constituyen el paradigma o matriz disciplinar de Kuhn (2006, pp. 279 y ss.): generalizaciones simbólicas, modelos, valores y ejemplares a los que las teorías particulares de la ciencia normal se adscriben. Veamos en qué consiste cada uno de esos componentes:

- Generalizaciones simbólicas: es el componente formalizable de la matriz disciplinar e incluye las leyes científicas en tanto formalismos abstractos vacíos de significado o aplicación 
empírica (los cálculos abstractos de la propuesta axiomática arriba revisada). Estas generalizaciones son incuestionables e irrefutables, y adquieren formas específicas conforme se aplican a la realidad; al mismo tiempo, son programáticas, preceden la investigación a modo de guía de manera que casi nunca entran en conflicto con la experiencia. Son las leyes específicas las que pueden ser contrastadas con la experiencia. Al ser irrefutables, cuando se las abandona, se produce una revolución científica.

- Modelos: son analogías heurísticas o compromisos ontológicos que construyen imágenes a partir de las cuales se pueden asimilar casos que requieren ser explicados. Los modelos producidos por un paradigma determinan qué puede ser aceptado como solución a un problema y condicionan la producción de ejemplares.

- Valores: es el conjunto de criterios axiológicos propios de una comunidad científica para evaluar su propia actividad: precisión, margen de error, fecundidad, coherencia, compatibilidad con otras teorías, entre los que cabe añadir la utilidad y la pertinencia social. Estos valores admiten jerarquías según aspectos exteriores a la actividad científica como los que se derivan del contexto social, económico, político o ideológico.

- Ejemplares: junto con las generalizaciones simbólicas, es el elemento más importante de un paradigma. Son ejemplos modélicos o casos que hacen de modelo: "son aplicaciones empíricas específicas del aparato formal que sirven de modelo o guía para el trabajo de resolución... o las partes de la realidad a las que se aplica el formalismo" (Díez y Moulines, 1997, p. 316). Así, el sistema solar es un ejemplar de la física newtoniana. Mediante los ejemplares, las situaciones nuevas se comprenden según otra anterior bien establecida: el sistema 
luna $x$ de Saturno puede ser entendido a partir de otro sistema tomado como modelo: Luna-Tierra. La ciencia normal produce exitosamente ejemplares por medio de los cuales los términos teóricos se cargan de contenido empírico. Los cambios científicos provocan modelos diferentes al punto de generar mundos inconmensurables, según nos posicionemos en uno u otro paradigma.

Cabe señalar que Kuhn no profundiza el término "teoría" por considerar que remite a estructuras mucho más limitadas en su naturaleza y alcance que los paradigmas. Así, da por sentado que varias teorías se articulan en torno a un paradigma, sin establecer con claridad el límite y las relaciones puntuales entre ambos instrumentos. En relación con otros aportes revisados en este libro, la propuesta de Kuhn cuestiona y con razón la perspectiva de Popper, según la cual la ciencia se transforma merced a su mismo empuje y dinámica interna y al calor del procedimiento lógico de falsación con la realidad; antes bien, son los aspectos histórico-sociales los que provocan las revoluciones científicas y que permiten, incluso, que una teoría perviva aun con datos en contra (Pozo, 2002, p. 18) o bien, sea abandonada por la falta de pertinencia con las expectativas sociales. Del mismo modo, en el mismo capítulo I, vimos cómo Morin asume el concepto de paradigma precisamente por su imprecisión y ductilidad que lo convierte en apto para explicar procesos de relación interteórica y entre conocimientos más amplios y abarcantes.

\section{Los programas de investigación de Lakatos}

Lakatos también conforma la revuelta historicista y su principal aporte consta en su obra La metodología de los programas de investigación, publicada en inglés, en 1968, con el título The methodology of scientific research programmes. Este autor afirma que la teoría fun- 
ciona como una red de miniteorías cuyos conflictos e inconsistencias respecto a la naturaleza o datos de observación pueden subsanarse modificando una parte de la red. Esa parte de la red es el programa de investigación, el concepto fundamental de su propuesta. Todo programa de investigación consta de dos componentes: el núcleo firme (ideas centrales) y el cinturón protector (ideas auxiliares) cuya misión es impedir que el núcleo pueda ser refutado empíricamente.

Ahora bien, la teoría de la gravitación de Newton, la teoría de la relatividad de Einstein, la mecánica cuántica, el marxismo, el freudianismo, son todos programas de investigación dotados cada uno de ellos de un cinturón protector flexible, de un núcleo firme característico pertinazmente defendido, y de una elaborada maquinaria para la solución de problemas. Todos ellos, en cualquier etapa de su desarrollo, tienen problemas no solucionados y anomalías no asimiladas. En este sentido todas las teorías nacen refutadas y mueren refutadas. (Lakatos, 1989, p. 9)

El núcleo vertebra y confiere continuidad a una teoría al mismo tiempo que determina dos tipos de reglas metodológicas: la heurística negativa (lo que se debe evitar) y la heurística positiva (lo que se debe asumir). La heurística negativa prohíbe aplicar la refutación al núcleo y evitar su derrumbe por medio de un cinturón protector de hipótesis auxiliares o complementarias que se pueden modificar. La heurística positiva establece los pasos para modificar la parte refutable del programa (el cinturón auxiliar y protector). Una teoría evoluciona según la aplicación de estos caminos heurísticos. Más arriba hemos visto cómo Morin asume este punto de vista (cfr. supra).

Pocos científicos teóricos implicados en un programa de investigación se ocupan excesivamente de las "refutaciones". Mantienen una política de investigación a largo plazo que anticipa esas refutaciones. Esta política de investigación, u orden de investigación, queda establecida, con mayor o menor detalle, en la heurística positiva del 
programa de investigación. La heurística negativa especifica el núcleo firme del programa que es "irrefutable" por decisión metodológica de sus defensores; la heurística positiva consiste de un conjunto, parcialmente estructurado, de sugerencias o pistas sobre cómo cambiar y desarrollar las "versiones refutables" del programa de investigación, sobre cómo modificar y complicar el cinturón protector "refutable".

La heurística positiva del programa impide que el científico se pierda en el océano de anomalías. La heurística positiva establece un programa que enumera una secuencia de modelos crecientemente complicados simuladores de la realidad: la atención del científico se concentra en la construcción de sus modelos según las instrucciones establecidas en la parte positiva de su programa. Ignora los contraejemplos reales, los "datos" disponibles. (1989, p. 55)

La falsación de una teoría se da por la aparición de una teoría mejor, por la irrupción de un programa de investigación progresivo con mayor capacidad para explicar e incorporar hechos nuevos frente a otras teorías o programas regresivos que explican lo ya conocido. La progresión - y no la revolución, como proponía Kuhn- puede ser de carácter teórico (progresión teórica), cuando establece predicciones nuevas, aunque no corroboradas y cuando una teoría se incluye en otra; o bien de carácter empírico, cuando corrobora alguna de las predicciones teóricas. Pero, en realidad, el potencial de progreso de un programa de investigación se relaciona con su capacidad de extender el potencial predictivo a nuevos dominios (Pozo, 2002, p. 21), configurar problemas y rendir predicciones.

Pero ¿cómo podemos distinguir un programa científico o progresivo de otro pseudocientífico o regresivo? [...] Pero todos los programas de investigación que admiro tienen una característica común. Todos ellos predicen hechos nuevos, hechos que previamente ni siquiera habían sido soñados o que incluso habían sido contradichos por programas previos o rivales. (Lakatos, 1989, p. 9) 
Lakatos asume a la vez que complejiza la idea de falsación de Popper - punto de vista que califica de falsacionismo ingenuo- relativizando sus alcances debido a que no necesariamente la falsación da de baja una teoría: también impulsa su reajuste y mejora. $\mathrm{Al}$ mismo tiempo, enriquece la falsación como un proceso producido no solo desde la empiría a la teoría, ya que ocurre en la confrontación entre teorías rivales cuando una teoría mejor sustituye a otra que, al ser superada, deja de ser vigente.

Pero entonces se desvanece el carácter claramente negativo del falsacionismo ingenuo; la crítica se hace más difícil pero también positiva, constructiva. Naturalmente, si la falsación depende de la aparición de teorías mejores, de la invención de teorías que anticipen hechos nuevos, entonces la falsación no es simplemente una relación entre una teoría y la base empírica, sino una relación múltiple entre teorías rivales, la "base empírica" original y el crecimiento empírico que tiene su origen en la confrontación. (1989, p. 40)

Lakatos rechaza la postura kuhniana de inconmensurabilidad entre las teorías cuando se transforman los paradigmas y adopta una perspectiva de continuidad que incluye el carácter acumulativo y sucesivo de las teorías. Sin embargo, tienen lugar cambios cualitativos ocasionales producidos por el cambio de un programa o de las ideas que componen su núcleo central. La caracterización de Morin ( cfr. supra) en torno a los elementos de la teoría se fundamenta claramente en la propuesta de Lakatos. El punto débil de la propuesta de Lakatos, en cambio, radica en la imprecisión del alcance o dimensión de los programas de investigación, cuestionamiento análogo al del paradigma de Kuhn. 


\section{Larry Laudan: la teoría, herramienta para la solución de problemas empíricos y conceptuales. Las tradiciones de investigación}

Laudan desarrolla un modelo de comprensión de la ciencia en su obra El progreso y sus problemas. Hacia una teoría del crecimiento cientifico ([1977] 1986) ${ }^{33}$, en la que describe, desglosa y complejiza la noción de "problema", el rol de la teoría respecto a estos (los problemas generan teorías y las teorías, problemas) y la manera en que las teorías se conectan e interactúan entre sí a la manera de tradiciones de investigación. Proporciona, así, una perspectiva distinta a la de Kuhn y Lakatos, que también se enfocan en la solución de problemas sin detenerse en sus implicaciones para construir un modelo muy dinámico y flexible que explica la ciencia y su progreso, a partir de la noción central de que "las teorías son un tipo de cosas que resuelven problemas".

Si los problemas son el punto central del pensamiento científico, las teorías son su resultado final. Las teorías son relevantes, son cognoscitivamente importantes, en la medida en que - y solo en la medida en que- proporcionan soluciones adecuadas a los problemas. Si los problemas constituyen las preguntas de la ciencia, las teorías constituyen las respuestas. La función de una teoría es resolver la ambigüedad, reducir la irregularidad a uniformidad, mostrar que lo que sucede es en cierto modo inteligible y predecible. (1986, p. 100)

Las credenciales de una teoría, o los criterios con que se las evalúa, no dependen de factores internos autorreferenciales como si

33 La obra de Laudan se divide en tres partes. En la primera, ofrece los criterios con los cuales clasifica diverso tipo de problemas; en la segunda, identifica los requisitos que permiten determinar "cuándo una teoría proporciona una solución aceptable a los problemas" (1986, p. 104), y en la tercera, aporta ejemplos de la historia de la ciencia que argumentan a favor de su tesis central. 
son verdaderas, debidamente corroboradas o bien confirmadas. Sus méritos radican en "si constituyen soluciones adecuadas a problemas relevantes". Su tesis central se expresa en la siguiente proposición:

Hay muchos objetivos inmanentes — no trascendentes - en cuyos términos podemos intentar una caracterización de la ciencia; podemos considerar que la ciencia se encamina hacia teorías bien comprobadas, teorías que predicen hechos nuevos, teorías que "salvan los fenómenos”, o teorías que tienen aplicaciones prácticas. Mi propuesta, más general que estas, es que el objetivo de la ciencia consiste en obtener teorías con una elevada efectividad en la resolución de problemas. Desde esa perspectiva, la ciencia progresa solo si las teorías sucesivas resuelven más problemas que sus predecesoras. (1986, p. 11)

Laudan, entonces, identifica minuciosamente las condiciones y requisitos para que un problema sea considerado como tal solo en relación con una teoría; y ofrece una tipología que articula y distingue dos tipos de problemas (1986, pp. 43 y ss. y 82 y ss.):

a. Problemas empiricos". Se refieren a los "problemas acerca del mundo" (aquellos que nacen de los datos de la realidad) en el sentido del dominio (el conjunto de objetos y hechos) de una ciencia dada. Los datos dependen de las teorías disponibles que les otorgan un marco de indagación para ser identificados y reconocidos como tales (las teorías nos dicen qué puede ser preguntable). Un hecho se convierte en problema cuando la teoría lo define como tal. La solución de estos problemas depende del estudio de los objetos del dominio y no tienen que ver con la explicación satisfactoria de un hecho. A estos problemas Laudan los denomina de primer orden. Pueden, a su vez, ser de tres tipos: a.1) problemas no resueltos; a.2)

34 El desarrollo in extenso de los problemas empíricos y su taxonomía tiene lugar en Laudan (1986, pp. 43 y ss.). 
problemas resueltos; a.3) problemas anómalos, aquellos no resueltos por una teoría, pero resueltos por una o más teorías alternativas. Estos últimos son más importantes que los problemas no resueltos para explicar el progreso de la ciencia. Así, uno de los rasgos del progreso científico "es transformar los problemas empíricos anómalos y no resueltos en problemas resueltos" (1986, p. 46). Así, es más importante solucionar los problemas empíricos antes que explicarlos (la ciencia tiene una carga muy fuerte sobre esto último).

b. Problemas conceptuales ${ }^{35}$. Se tratan de características de las teorías y no tienen existencia independiente fuera de ellas. Pueden, a su vez, de dos tipos: b.1) internos (inconsistencias y ambigüedades); y b.2) externos, aquellos que denotan conflictos del tipo inconsistencia o incompatibilidad lógica entre y respecto a otras teorías o marcos doctrinales. Configuran problemas a ser resueltos más determinantes que los empíricos y que las anomalías. Respecto a los problemas conceptuales externos, Laudan (p. 87) propone la siguiente taxonomía de dificultades que provocan problemas conceptuales: a) dificultades intracientíficas, referidas al marco de la práctica científica; b) dificultades normativas, que tienen que ver con el ámbito metodológico de una teoría. Ante una inconsistencia, las alternativas consisten en cambiar la teoría en razón de la metodología de otra teoría, o cambiar la metodología de una teoría en razón de los aportes de otra teoría; c) dificultades relativas a la visión del mundo, que denotan incompatibili-

35 El desarrollo extenso de los problemas conceptuales y su taxonomía tiene lugar en Laudan (1986, pp. 82 y ss.). 
dades con otros cuerpos de conocimientos no científicos o creencias $^{36}$. A estos problemas los denomina de orden superior.

La distinción entre problemas empíricos y conceptuales es clave, y la importancia de los problemas conceptuales es tal que "cualquier teoría acerca la naturaleza de la ciencia que no encuentre una función para los problemas conceptuales, pierde toda pretensión de ser una teoría acerca de cómo ha evolucionado realmente la ciencia" (Laudan, 1986, p. 100). Las teorías funcionan bien casi siempre sin un ajuste total entre sus elementos, según una lógica y pragmática muy flexibles y de soluciones aproximadas, en las que resultan irrelevantes atributos como la verdad o la falsedad, tal como lo demuestra la historia de la ciencia. Por lo tanto, las credenciales de una teoría hacen de la evaluación teórica un asunto comparativo, según el cual una teoría "debe vérselas con otras" (teorías rivales) en relación con la resolución de un problema. Esas credenciales dependen del saldo favorable en la solución de problemas empíricos, anomalías y problemas conceptuales, donde la teoría no responde desde sí, sino en relación con su capacidad de resolución respecto a otras teorías rivales. Así los supuestos del modelo de explicación del progreso científico, una categoría que no tiene nada que ver con el progreso ético o moral, son los siguientes:

(1) El problema —empírico o conceptual — resuelto es la unidad básica del progreso científico; y (2) el objetivo de la ciencia es ampliar al máximo la esfera de problemas empíricos resueltos, al tiempo que reducir al mínimo el ámbito de problemas anómalos y conceptuales. (1986, p. 100)

36 Respecto a esto último, es llamativa la taxonomía bipartita de las creencias entre científicas y no científicas, e incluir en estas últimas la metafísica, la lógica, la ética y la teología, lo cual revela que la línea demarcatoria está constituida por el modelo de las ciencias naturales donde la empiría juega un rol crucial. 
Respecto a la metateoría, Laudan concibe que la teoría está constituida por redes proposicionales de distinto registro y alcance (1986, pp. 105 y ss.) que funcionan según dos niveles de generalidad diferenciados. Así, las del primer tipo están constituidas por un conjunto de doctrinas relacionadas (hipótesis o axiomas o principios) con las cuales lleva a cabo predicciones experimentales y explicaciones detalladas de los fenómenos naturales. A este tipo de teorías, relacionadas directamente con su campo fenoménico y con sus especificaciones, las denomina microteorías. Las del segundo tipo están constituidas por un conjunto de doctrinas o supuestos mucho más generales y no tan directamente relacionables o corroborables con un ámbito empírico. De este tipo son las familias de teorías (ejemplo: las teorías de la evolución) u otras que pueden conectarse con una gama muy amplia de especificaciones, a pesar de la enorme diferencia entre sí (ejemplo: la teoría cuántica). A las del segundo tipo, Laudan las denomina tradiciones de investigación y las equipara con las macroteorías o las superteorías de Lakatos.

La tradición de investigación, entonces, se refiere al concepto amplio de teoría, tal como se describe en el segundo caso, consta de al menos los siguientes rasgos iniciales: un tipo de asociación entre teorías, supuestos compartidos y temporalidad larga (1986, pp. 113 y ss.):

- Conjunto de teorías específicas. Son aquellas teorías asociadas que concretan o ejemplifican las tradiciones de investigación, sus compromisos ontológicos y formas de proceder. Algunas de las teorías específicas serán contemporáneas; y otras, herederas temporales de teorías anteriores. Y no todas serán consistentes entre sí. La función de las teorías específicas "es explicar todos los problemas empíricos del dominio 'reduciéndolos’ a la ontología de la tradición de investigación” (p. 114). 
- Supuestos compartidos. Son aquellos elementos primeros que individualizan las tradiciones de investigación y distinguen una tradición de otra. Son de dos tipos: a) los compromisos metafísicos (conjunto de creencias acerca de qué tipos de entidades y procesos constituyen el dominio de la investigación); y b) las normas epistémicas y metodológicas (cómo debe investigarse el dominio, cuál es el conocimiento de fondo intocable, normas de verificación de hipótesis, cómo se recogen y analizan los datos). Ambos dan forma a la heurística (orientaciones para la investigación) y a la axiología (normas de evaluación). Toda tradición propone directrices de cómo modificar o transformar teorías. Estos supuestos funcionan unas veces como "síes" (alientan rutas) y otras como "noes" (limitan).

- Temporalidad larga. A diferencia de las teorías específicas, las tradiciones de investigación se caracterizan por una larga historia frente a la corta vida de muchas teorías.

La función total de las tradiciones de investigación es proporcionar "las herramientas decisivas que necesitamos para resolver problemas, tanto empíricos como conceptuales", y, además, otorgar el marco para identificar y expresar teóricamente esos problemas. Por lo tanto, una tradición de investigación se evalúa según su capacidad de resolución de problemas, y por su potencial para crear y generar problemas empíricos y conceptuales. Una tradición no es evaluada en términos de ser confirmada o refutada de verdadera o falsa, o de poseer o no consistencia ontológica o metodológica: "Una tradición de investigación puede tener un éxito enorme en la generación de teorías fructíferas y ser, sin embargo, deficiente en su ontología y metodología” (1986, p. 118). Las tradiciones de investigación son, en rigor, "criaturas históricas... creadas y articuladas en un medio intelectual concreto, colaboran en la producción de teorías específicas y — como todas las demás instancias históricas- crecen y de- 
clinan" (p. 133). Pero también se transforman con el tiempo debido a los siguientes factores: debido a cambios en alguna de sus teorías específicas subordinadas, o cambios en los elementos nucleares más básicos (contra Kuhn y Lakatos que afirman que ese núcleo básico es rígido y no puede cambiar).

Las tradiciones de investigación pueden coexistir una al lado de otra. Una tradición no necesariamente sustituye a otras, como sugiere Kuhn cuando afirma que el período de ciencia revolucionaria supera y sustituye al período de ciencia normal: así, la cohabitación entre teorías o una familia de estas es la regla, tal como lo demuestra la historia de la ciencia. Pero no solo pueden coexistir, también es posible que distintas tradiciones se integren entre sí de dos modos diferentes: cuando una tradición se injerta en otra, sin ninguna modificación importante en los supuestos de ninguna de ellas; o cuando su fusión demanda el rechazo de algunos elementos fundamentales incompatibles

Otros criterios de evaluación de las tradiciones de investigación se relacionan con dos ámbitos: el de la comparabilidad y el del contexto. La comparabilidad se despliega en dos modos de evaluación: a) adecuación de las últimas teorías de una tradición a la resolución de problemas en un momento dado (evaluación sincrónica); b) progresividad, para establecer si a lo largo del tiempo la tradición conservó, incrementó o perdió la capacidad de resolver problemas (evaluación diacrónica). La evaluación de las tradiciones de investigación tiene lugar, además, en dos contextos distintos: a) contexto de aceptación que ocurre cuando la comunidad o un grupo de científicos decide considerar como si fuese verdadera o dignas de crédito una tradición o un grupo de teorías, cuyo criterio óptimo debería ser su capacidad de resolución de problemas; $\mathrm{y} b$ ) contexto de utilización: algunas veces se escogen teorías o tradiciones de investigación no por la confianza o el crédito que se deposita en ellas, sino por ser una alternativa productiva respecto a 
las más aceptadas; porque hay buenas razones para trabajar con teorías poco aceptadas (Laudan, 1986, p. 149). Y este factor es una causa muy frecuente del progreso científico.

La noción de que una teoría soluciona problemas no es nueva ni original. Laudan reconoce que otros lo habían afirmado antes que él, incluido Popper (cfr. supra) y tanto Kuhn como Lakatos le conceden su lugar a la empresa de solución de problemas. Pero ninguno de ellos se había tomado en serio la afirmación sin ir más allá de la retórica. Laudan, de hecho, es el primero que elabora un modelo de comprensión del progreso científico a partir de la práctica concreta de la historia de dos ciencias: las ciencias naturales y la física, donde la relación entre el núcleo axiomático y la empiría ha sido siempre problemática. Describe cómo las teorías y las tradiciones de investigación se justifican a sí mismas por su capacidad de solucionar problemas, desglosando sus implicaciones epistémicas y metodológicas al punto de ser el primero y el único — afirma él mismo- que concede a los problemas conceptuales un rol clave en el progreso de científico, porque sin ellos resultaría imposible entenderlo.

Su reflexión surge en medio de la percepción generalizada de la filosofía de la ciencia que atribuye a los problemas empíricos el primado en la explicación del cambio científico y a los que se les atribuye la causa de la preferencia de una teoría por otra. Kuhn y Lakatos, por ejemplo, adhieren a esa tendencia (Laudan, 1986, p. 100) y Popper es otro ejemplo ya revisado de la primera importancia concedida a la empiría, capaz de falsar una teoría si esta no encaja con ella. Laudan propone, en cambio (coincidiendo con Lakatos, como hemos visto), que la empiría no necesariamente falsea una teoría; más bien induce a su mejora y la impulsa a favorecer un mejor ajuste entre sus elementos (p. 100). 
Laudan va mucho más allá y llega a afirmar que el progreso de la ciencia depende no solo de la solución de problemas empíricos, sino también de la adecuación del sistema normativo de la teoría respecto a la indagación de cierto tipo de problemas. Así, su propuesta contribuye a la toma de conciencia de que tanto los enfoques inductivos como el hipotético deductivo (del que Popper es un prominente representante), hoy considerado la práctica dominante en la ciencia, obedecen a momentos históricos distintos, en los que la reflexión debía, primero, dar cuenta de datos observables y al alcance de la mano (enfoque inductivo) y, más tarde, debido a los avances de la física que requerían dar cuenta de dominios no tan accesibles a la observación, resultaron más adecuados los enfoques hipotético-deductivos.

Por ello, el "reconocimiento de problemas conceptuales normativos es una fuerza de la evolución histórica de la ciencia mucho más potente de lo que han admitido algunos historiadores de la ciencia” (Laudan, 1986, p. 94). Igual de importantes son otros factores relacionados con doctrinas no científicas ligadas a la visión del mundo y a las controversias metafísicas, así como los conflictos ideológicos y morales que impulsan la ciencia en diversas direcciones. Estos no constituyen pseudoproblemas sino factores que tensionan la ciencia e inciden positivamente en la solución de problemas.

\section{Comentario e implicaciones}

Los aportes revisados en el capítulo II se refieren a los aspectos menos familiares y accesibles de la teoría de la teoría, los cuales, queramos o no, operan subyacentes en la práctica cotidiana de la ciencia y la enseñanza universitaria, especialmente respecto al carácter modélico de la teoría cada vez más presente en la economía, las ciencias de la vida y las ciencias técnicas. Acceder a las diversas opciones que 
permiten de una u otra manera comprender los elementos de las teorías y sus relaciones, así como la manera en que las teorías se articulan entre sí, es de mucha utilidad y pertinencia. Veamos por qué:

Las corrientes axiomáticas nos llaman la atención sobre el encadenamiento de proposiciones de progresivo grado de abstracción que constituyen las teorías (enunciados empíricos, generalizaciones empíricas, axiomas con sus respectivos términos) cuyas reglas de control obedecen a la lógica. No dudamos de que se trata de una aproximación relevante al hecho de que toda teoría no se reduce al conjunto de enunciados empíricos referidos al dominio de la realidad que buscan comprender, sino que incluye otros de carácter puramente lógico y axiomático, de un alto grado de abstracción y generalidad. Asimismo, es una propuesta que nos ofrece una primera definición de los elementos básicos de una teoría y de sus reglas del juego en el terreno de la lógica y del encadenamiento de proposiciones.

El análisis estructural de las teorías no está muy presente en la metateoría de las ciencias sociales y, a decir verdad, tampoco es frecuente y común observar su despliegue en ciencias como la biología, la física o la genética, no obstante existir descripciones teóricas como las aplicadas por Lorenzano (2002a), para la reconstrucción estructural de la bioquímica o para la teoría del gen (2002b); y por Casanueva (2002) para analizar redes teóricas sobre la hibridación mendeliana. A pesar de las búsquedas, no logramos identificar análisis similares aplicados a las ciencias sociales; no obstante, hemos reconocido elementos que resultan familiares para un tipo de sensibilidad epistémica ampliamente difundida en el análisis de la realidad sociocultural. Estos son los siguientes:

a. Toda teoría relaciona dos ámbitos: el contenido conceptual y el dominio de la realidad que se busca comprender según 
una relación entre ambos de aproximación y verosimilitud. Es decir, nos advierte de que lo real no es reductible a la teoría ni la teoría es una copia de lo real, pues se concibe, en el fondo, a partir de una lectura teórica. Se refuerza la idea de que toda teoría remite a un núcleo básico, paradigmático, que busca estabilidad y un cinturón protector que genera una dinámica defensiva de dicho núcleo.

b. La lectura estructural atribuye importancia a los aspectos pragmáticos constitutivos de la teoría y la comunidad de científicos es el más decisivo porque se constituye en una comunidad de sentido que sanciona y determina las preferencias y opciones teóricas más allá de las determinantes lógicas. Por ello, la ciencia no es un escenario autorregulado por sus propios códigos y procedimiento, pues depende para su desarrollo de los intereses sociales de los usuarios. Al mismo tiempo, refuerza la idea de que no existen razones esenciales para considerar la ciencia como una forma privilegiada y mejor de conocimiento: son los diversos usuarios que sancionan diversas formas de saberes según sus perspectivas e intereses.

c. Las teorías son realidades dinámicas y no las podemos entender solo a partir de los elementos que las constituyen en un momento dado de su evolución: es necesario, además, establecer su recorrido a través del tiempo, a fin de constatar la persistencia de los elementos estables y la transformación de los elementos accidentales.

d. Asimismo, toda teoría no se reduce a sus conceptos clave, sino a las redes de especificación y concreción que la refieren a diversos dominios de lo real y de aplicación cada vez más específicos. El concepto de teoría-red contiene ricas implicaciones para las ciencias sociales, pues nos ayudan a compren- 
der la necesidad de articular diversos niveles de especificidad en la explicación teórica.

e. Toda teoría no es un corpus autosuficiente y autorreferenciado definido por sus propios términos: implica relaciones y vínculos necesarios con otras teorías. En efecto, en antropología usamos términos prestados, dados y desarrollados no solo por fuera de las teorías referenciales. Antes bien, provienen de otros entornos disciplinares; y viceversa, constatamos que muchos de los conceptos anidados en la antropología se han difundido ampliamente hacia otros entornos como la política y el sentido común, y son asumidos, también, como dados.

La perspectiva semántica, sin duda alguna, es la que gana cada vez mayor importancia en la academia debido, entre otras razones, a la creciente necesidad de modelizar o correr modelos para ordenar y manejar datos cada vez más numerosos y diversos obtenidos y correlacionados mediante los recursos informáticos, por ejemplo, para explicar y predecir el cambio climático, los fenómenos astronómicos y las situaciones económicas. La enorme cantidad de datos requeridos para estos y otros dominios de la ciencia implica incluirlos en un modelo capaz de dar cuenta de ellos. Por lo tanto, las teorías no solo ofrecen explicaciones causales y externas a los fenómenos de cualquier tipo sino y sobre todo proveen de marcos interpretativos, porque ellas mismas constituyen una interpretación de la realidad, sin los cuales, los datos son significantes vacíos.

Para las ciencias sociales y, en general, las corrientes historicistas son muy útiles porque, a diferencia de la corriente axiomática, remarcan más allá de la lógica los aspectos pragmáticos e históricos que intervienen en el desarrollo científico, de tal modo que resulta inadmisible un tipo de análisis de las teorías que excluya las comunidades de sentido y el contexto histórico que las animan y vertebran entre sí. Al- 
gunos cuestionan que Laudan encierre la ciencia y la teoría en el marco estricto de la solución de problemas, pues no es una condición que explica por sí misma el progreso científico. No pocas veces la dinámica del conocimiento no va a la par de la solución de problemas y, sin embargo, es posible afirmar que el conocimiento progresa. Un crítico del concepto de progreso científico, tal como lo definen Laudan y Kuhn, es Alexander Bird (2007) que considera esta postura regresiva, ya que el progreso de la ciencia tiene que ver con la acumulación de conocimiento teórica y metodológicamente justificado ${ }^{37}$.

El aporte de Laudan es insustituible para comprender la epistemología del problema y potente para describir la dinámica viva así como el funcionamiento creativo de las teorías que rinden epistémicamente a pesar de los desajustes y los interrogantes pendientes. Así es como funciona la ciencia en realidad. Su enfoque centrado en la capacidad de la teoría para la solución de problemas nos recuerda al filósofo estadounidense Charles Sanders Peirce (1839-1914), padre del pragmatismo y la semiótica, para quien un sistema de teorías debería tomar en cuenta aquellas que de veras han solucionado problemas. El innegable aire de familia con la tradición de Peirce no es casual en Laudan y refleja una opción epistémica clara que se expresa, además, en su rol de presidente de la International Peirce Society en el 2009.

Consideramos que Laudan es muy importante, además, porque contribuye a tomar muy en cuenta el aspecto metodológico como una dimensión esencial e indisociable de la teoría y alerta sobre la imposibilidad de enajenar de esta los métodos y las técnicas que le dan vida y sentido, admitiendo, a la vez, una relación muy flexible y epistémicamente productiva entre los principios axiomáticos y las metodologías.

37 Para el análisis de los argumentos de Bird, también en contra de la corriente semántica, ver Islas Mondragón (2015). 
Los autores referidos en la última sección (Kuhn, Lakatos y Laudan) aportan elementos que vertebran una matriz descriptiva de las teorías, o de un conjunto de estas emparentadas según programas o tradiciones de investigación, tal como la que proponemos en la Tabla 9 que reinterpreta y añade algunos aspectos a los ya revisados. Los ejes descriptivos y los rasgos que los constituyen son útiles para desarrollar marcos teóricos que establecen las relaciones de continuidad o ruptura de las opciones conceptuales y metodológicas respecto a otras propuestas.

Tabla 9

Matriz descriptiva de teorías

\begin{tabular}{|l|l|}
\hline \multicolumn{1}{|c|}{ Ejes descriptivos } & \multicolumn{1}{c|}{ Componentes } \\
\hline Supuestos compartidos & $\begin{array}{l}\text { Compromisos ontológicos: cómo concibe la realidad y la historia; } \\
\text { la cultura, la sociedad y la persona. Cómo concibe la identidad } \\
\text { y la acción social. } \\
\text { Compromisos epistemológicos: cómo concibe el conocimiento. } \\
\text { Compromisos éticos y políticos: cómo concibe el proyecto de so- } \\
\text { ciedad y de convivencia. }\end{array}$ \\
\hline $\begin{array}{l}\text { Heurística } \\
\text { Normas epistémicas }\end{array}$ & $\begin{array}{l}\text { Rol del conocimiento científico. } \\
\text { Enfoque de la teoría: explicativo, estructural, interpretativo, } \\
\text { complejo. } \\
\text { Criterios de evaluación: lógica, significatividad, relevancia, capa- } \\
\text { cidad de resolución de problemas, potencial transformador... }\end{array}$ \\
\hline Normas metodológicas & $\begin{array}{l}\text { Procedimientos investigativos. } \\
\text { Técnicas connaturales. } \\
\text { Énfasis metodológicos. } \\
\text { Encadenamientos discursivos. }\end{array}$ \\
\hline $\begin{array}{l}\text { Áreas de aplicación y } \\
\text { solución de problemas } \\
\text { misma tradición }\end{array}$ & $\begin{array}{l}\text { Aplicaciones conceptuales: área de problemas teóricos. } \\
\text { Aplicaciones empíricas: área de resolución de problemas sociales, } \\
\text { educativos, etc. } \\
\text { Marco empírico: área de la realidad que le es más connatural. }\end{array}$ \\
\hline $\begin{array}{l}\text { Tradición de pensamiento en que se inserta la teoría. } \\
\text { Cercanías, continuidades y rupturas con otras teorías. }\end{array}$ \\
\hline
\end{tabular}

Elaboración de los autores. 